\title{
Lantana camara AND BUTTERFLY ABUNDANCE IN AN URBAN LANDSCAPE: BENEFITS FOR CONSERVATION OR SPECIES INVASION?
}

\author{
SWARNALI MUKHERJEE ${ }^{1}$, SOUMYAJIT BANERJEE ${ }^{1}$, PARTHIBA BASU ${ }^{1}$, GOUTAM K \\ SAHA $^{1}$, GAUTAM ADITYA $^{1,2^{*}}$ \\ ${ }^{1}$ Department of Zoology, University of Calcutta, 35, Ballygunge Circular Road, Kolkata 700019, India \\ ${ }^{2}$ Department of Zoology, The University of Burdwan, Burdwan 713104, India; e-mail: gautamaditya2001@gmail.com \\ * Author for correspondence
}

\begin{abstract}
Mukherjee S., Banerjee S., Basu P., Saha G. K., Aditya G.: Lantana camara and butterfly abundance in an urban landscape:benefits for conservation or species invasion? Ekológia (Bratislava), Vol. 34, No. 4, p. 309-328, 2015.

Urban landscapes host a range of diverse plants that, in turn, facilitate maintenance of different species of pollinators, including butterflies. In this context, the importance of Lantana camara, an invasive plant species, was assessed highlighting its role in maintenance of butterfly diversity, using Kolkata, India as a study area. Initial study revealed consistent presence of L. camara in both urban and rural sites with at least 25 different butterfly species association. The proportional relative load and the preferences of butterfly species for the each plant species were inclined towards $L$. camara. Irrespective of the sites, the diurnal and seasonal variations in the butterfly species abundance varied with the flowering pattern of $L$. camara. A positive correlation of different butterfly species with the flowering time and number of $L$. camara was for all the sites. The segregation of the L. camara associated butterfly species was made following discriminant function analysis using the extent of flower density of L. camara as explanatory variable. Despite being an invasive species, it is apparent that L. camara can be a prospective host plant that facilitates sustenance of butterflies in both urban and rural sites. Thus, existence of L. camara in urban gardens and forests may prove beneficial in sustenance of the butterflies.
\end{abstract}

Key words: Lantana camara, butterfly, flower density, urban greening, conservation.

\section{Introduction}

Plants in urban landscapes enable sustenance of several ecosystem functions and thereby act as elements for conservation planning and management. In cities and towns, spaces for plants and trees are common to endure the scenic beauty and enhance air quality (Haq, 2011). The sides of the streets and small patches of gardens in housing areas are constituents of the urban greening that carry immense potential in conservation management (Gaston et al., 2005; Mathieu et al., 2007). Among the different types of plant aggregates observed in cities and towns, bushes are common comprising small herbs, shrubs and grasses. Bushes offer 
sustenance of various animals and microbes as dependent taxa and thus, are crucial elements in maintenance of the biological diversity (Hermy, Cornelis, 2000; McFrederick, LeBuhn, 2006). The forms of the plants promoted for urban greening vary in taxonomic identity and morphological features depending on the specific requirements of the geographical region (Godefroid, Koedam, 2007). Patches of urban gardens and forests are valuable sites to reduce the alteration and reduction in the natural communities due to the different development programmes of urban areas. Thus, urban greening and the urban forestry is being given priority to continue with the propagation of green plants and their significance in the lives of urban dwellers (Haq, 2011).

The relative value of the bushes and sedges in the street sides depends on the species of plants constituting these bushes. The indigenous nature of the plants is more important in the context of preventing the entry of the invasive species and continues with the propagation of the plants of economic and ecological values. However, often this is not the case in urban conditions where the bushes are dominated by the vegetations that are invasive in nature, with least chance of regulation (Faeth et al., 2011). With time, the invasive plant species colonise and establish as a natural component of the urban conditions (Mack et al., 2000). One example is that of Lantana camara (Linnaeus, 1753) (Family: Verbenaceae) (Fig. 1), a weed plant, native to South America that has spread globally and established itself as a common species in bushes. Changes in the soil condition and the composition of the native plant composition are considered as an effect of the invasion of $L$. camara (Hegde et al., 1996; Raizada et al., 2008). However, contrary to the prevailing paradigm of the ill effects of invasive plants, the species diversity increases due to the presence of L. camara, and the survival of seedlings of the associated native plants are also enhanced (Murali, Siddappa Setty, 2001). Despite the invasive nature, L. camara is considered as a resource with multiple benefits, including medicinal value (Patel, 2011) and therefore, may prove useful in areas where the invasive weed has colonised for a long time period (Kannan et al., 2014). This is relevant for situations where the plant can be considered for enhancing beauty and facilitating the conservation of associated species such as butterflies. Mutualism between different butterfly species with L. camara is recorded from different parts of the world where the latter is considered as an invasive species. Butterflies exploit L. camara as a source of food (Weiss, 1997; Penz, Krenn, 2000; Andersson, Dobson, 2003), oviposition site, larval development (Jothimani et al., 2014) in lieu of pollination (Dronamraju, 1960; Schemske, 1976; Faegri, van der Pijl, 1979; Proctor et al., 1996) and successful transfer of the mites (Boggs, Gilbert, 1987). Based on this mutualistic relationship, the number of dependent butterfly species can serve as a surrogate to measure the relative importance of a plant species. Abundance-based association provides an estimate of the potential of a plant species in sustaining and facilitating conservation of butterflies. Thus, in the present study, an attempt was made to evaluate the potential role of $L$. camara in promoting butterfly conservation in urban landscapes using Kolkata, India as a model geographical area.

Conservation of butterflies are being emphasised for several reasons, including their potential value as indicator species and functions that collectively add to the ecosystem services (van Strien et al., 2009). Successful conservation and promoting populations of butterfly depend on the availability of host plants in the concerned landscapes (Smallidge, Leopold, 


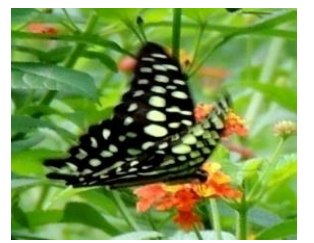

Tailed Jay [Graphium agamemnon (Linnaeus,1758)]

Papilionidae

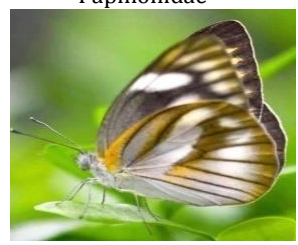

Striped Albatross

Appias libythea (Fabricius, 1775)

Pieridae

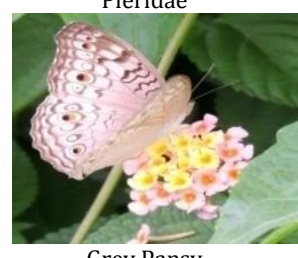

Grey Pansy

[Junonia atlites Linnaeus, 1763]

Nymphalidae

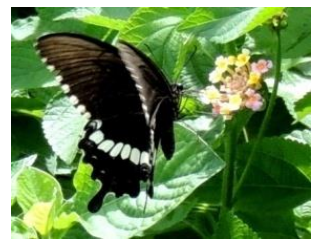

Common Mormon

[Papilio polytes

Linnaeus, 1758]

Papilionidae

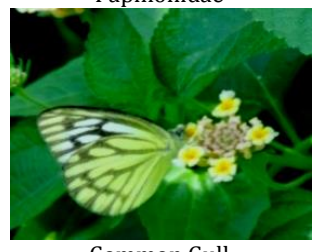

Common Gull

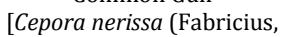

1775)

Pieridae

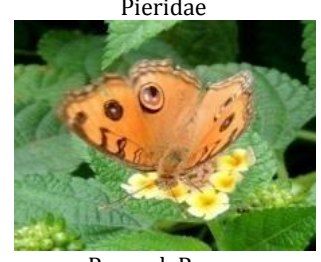

Peacock Pansy [Junonia almana

(Linnaeus, 1758)]

Nymphalidae

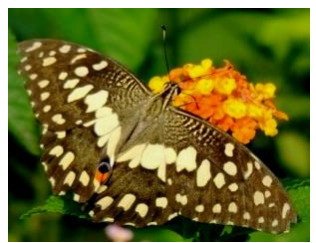

Lime Butterfly

[Papilio demoleus Linnaeus, 1758]

Papilionidae

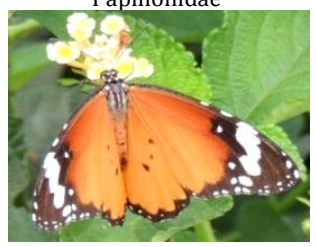

Plain Tiger

[Danaus chrysippus

Linnaeus, 1758]

Nymphalidae

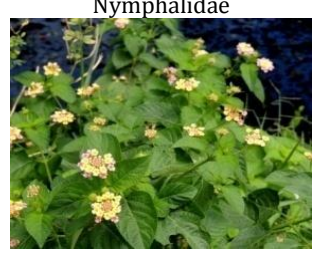

[Lantana camara

(Linnaeus, 1753)]

Verbenaceae)

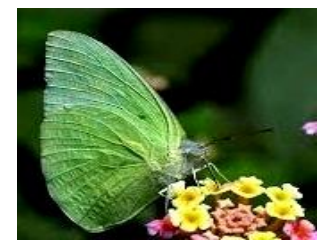

Common Emigrant [Catopsilia pomona (Fabricius, 1775)]

Pieridae

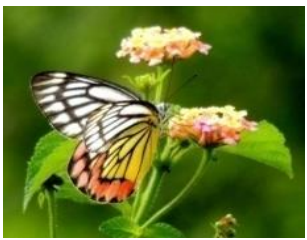

Common Jezebel

[ Delias eucharis

(Drury, 1773)]

Pieridae

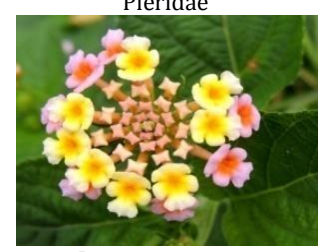

[Lantana camara

(Linnaeus, 1753)]Verbenaceae

Fig. 1. Photos of butterflies and the plant selected for the present survey. The photographs were taken during field survey irrespective of sites. The orange, pink and yellow colours of the flowers of Lantana camara are shown in the figures.

1997). In urban context, the available spaces for the host plants are dwindling and in many instances, restricted to the gardens and forests. The characteristic plant species assemblages and the relative load to host butterfly species will be a determinant factor for the successful conservation of the butterflies. The selection and further use of the plant species in the conservation of butterflies can be made through the estimation of the relative load of the butterfly species. Using this proposition as a basis, the present study was conducted with initial assessment of the butterfly species association in the different plant species in the landscapes, followed by specific estimate of the plant L. camara as surrogate species to enhance butterfly populations. In the present study area, butterfly association with L. camara is known since long (Dronamraju, 1958, 1960) and has been considered as a factor for the propagation of butterflies. The dependence of butterflies on L. camara can be deduced through a correspondence between the densities of the flowers and butterflies in a particular space. In the 
present study, the relation between the flowering density and the abundance of the butterflies was also measured to highlight the dependence of the butterflies on L. camara. The interaction between plants and butterflies represent mutualism where benefits towards reproductive success are shared by both the groups. Invasive flowering plants may adopt the strategy of hosting higher butterfly species to ensure faster spread and successful invasion of space as demonstrated by Tamarisk spp. (Nelson, Wydoski, 2013) and several plants in California, USA (Shapiro, 2002; Graves, Shapiro, 2003). Similarly, in the present context, the association of butterflies with the invasive species L. camara is being assessed to justify their possible role in conservation of butterflies. Equally, the role of the butterfly species in mediating pollination and thus, perpetuation of L. camara can be identified. Although, butterflies are among the different insect species involved in pollination of L. camara (Dronamraju, 1960; Mathur, Mohan Ram, 1978; Mohan Ram, Mathur, 1984), identification of the concerned species of butterflies may provide insight towards the understanding of the propagation of the invasive species. Thus, the objective of the present work is focussed on the estimation of the extent of butterfly species association with $L$. camara and to leave the decision and the debate on the utility of the invasive species in conservation programme.

\title{
Material and methods
}

\section{Study area}

The study was carried out in Kolkata, India and its adjoining areas by selecting three different study sites on the basis of the habitat features (human population, agricultural land, etc.). Each study site was selected mainly by on-site visit and Google Earth image. There was a central point in each study site and the coordinate of the central points were recorded by Global Positioning System (GPS) (GPSMAP ${ }^{\circ} 76 \mathrm{Cx}$, Garmin, Kansas, USA). The survey was conducted around each central point. The places selected for the study were Kuliagharhat ( $\left.22^{\circ} 53^{\prime} 24.17^{\prime \prime} \mathrm{N}, 88^{\circ} 28^{\prime} 8.93^{\prime \prime} \mathrm{E}\right)$ as rural, Halisahar as suburban $\left(22^{\circ} 55^{\prime} 20.05^{\prime \prime} \mathrm{N}, 88^{\circ} 26^{\prime} 6.77^{\prime \prime} \mathrm{E}\right)$ and Dumdum as urban $\left(22^{\circ} 37^{\prime} 16.67^{\prime \prime} \mathrm{N}, 88^{\circ} 23^{\prime}\right.$ 34.31 ” E) sites.

\section{Study organisms}

\begin{abstract}
The butterflies associated with the vegetation in the bushes of the study constituted the study organisms. Among the constituent species in the vegetation, the flowering plants used as nectar sources by butterflies (Tiple et al., 2009) were considered with emphasis on the invasive species L. camara. In the initial study, the abundance of L. camara remained considerably high, justifying its inclusion as a focal plant in the continuous study. The plant L. camara, is a woody shrub, having prickly stem, opposite, ovate, subacute leaves with truncate base and are crenate, serrate,

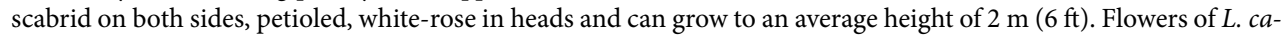
mara (Fig. 1) undergo change in colour with ages (Mathur, Mohan Ram, 1978; Mohan Ram, Mathur, 1984). Younger flowers have pink buds and yellow flowers while the aged ones have orange, scarlet and magenta flowers. Both the younger and aged flowers are found in the same inflorescence. It can tolerate wide range of ecological conditions and thrives well even in disturbed conditions. Pollination is attributed to butterflies, moth, bees and thrips (Goulson, Derwent, 2004). They exhibit allelopathic impact on commercial plants such as chilli, cabbage but did not affect germination of spinach and cucumber seeds (Sahid, Sugau, 1993). The benefits derived from L. camara include its use as drugs, improvement of soil quality and regulation of microbes and vectors (Patel, 2011).
\end{abstract}

\section{Sampling period and time}

A pilot study was conducted for a period of 6 consecutive weeks. Following the primary results, continuous survey was conducted for a period of 1 year, between October 2011 and September 2012. To infer about the seasonal pat- 
terns in butterfly abundance in relation to flower number, the entire year was divided into four seasons viz. summer (March-May), monsoon (June-August), post-monsoon (September-November), winter (December-February) and the survey was initiated in October, 2011, which coincides with the peak flowering time for Lantana (Sajjad et al., 2012) and thus, the probability of a relatively high abundance of associated butterfly species. The seasonal meteorological variation with some features of study sites is presented through Table 1 . The transects were monitored during $0800 \pm 2 \mathrm{hrs}$ till noon (1200 $\pm 2 \mathrm{hrs}$ ) and during $1400 \pm 2 \mathrm{hrs}$ and $1600 \pm 2 \mathrm{hrs}$ depending on the season and availability of sunlight.

T a b l e 1. Description of study sites based on their location (L), size of the area covered for the survey $\left(\mathrm{A}\right.$ in $\left.\mathrm{km}^{2}\right)$, elevation of the specific sites from the sea level (EL, in $\mathrm{m}$ ) and average annual precipitation (AAP, in mm) and Variation in monthly meteorological data (mean $\pm \mathrm{SE}$ ) of temperature (TEMP), relative humidity $(\mathrm{RH})$ and rainfall $(\mathrm{RF})$ of the urban suburban and rural areas recorded during the study period (2011-2012).

\begin{tabular}{|l|c|c|c|c|c|c|c|c|c|}
\hline \multirow{5}{*}{} & \multicolumn{3}{|c|}{ Urban (Dumdum) } & \multicolumn{2}{c|}{ Sub Urban (Halisahar) } & \multicolumn{3}{c|}{ Rural(Kuliagharhat) } \\
\cline { 2 - 11 } & A & EL & AAP & A & EL & AAP & A & EL & AAP \\
\cline { 2 - 11 } & 10 & 16 & 3.307 & 8 & 15 & 4.007 & 8 & 13 & 4.207 \\
\cline { 2 - 11 } & TEMP & RH & RF & TEMP & RH & RF & TEMP & RH & RF \\
\hline \multirow{3}{*}{ PM } & $27.29 \pm$ & $76.73 \pm$ & $3.48 \pm$ & $26.59 \pm$ & $76.03 \pm$ & $4.18 \pm$ & $26.39 \pm$ & $75.83 \pm$ & $4.38 \pm$ \\
& 0.53 & 1.81 & 1.07 & 0.17 & 1.11 & 1.77 & 0.37 & 0.91 & 1.97 \\
\hline \multirow{3}{*}{ Winter } & $20.67 \pm$ & $65.60 \pm$ & $0.45 \pm$ & $19.97 \pm$ & $64.90 \pm$ & $1.15 \pm$ & $19.77 \pm$ & $64.70 \pm$ & $1.35 \pm$ \\
& 0.55 & 1.83 & 0.41 & 0.15 & 1.13 & 1.11 & 0.35 & 0.93 & 1.31 \\
\hline \multirow{3}{*}{ Summer } & $29.48 \pm$ & $43.87 \pm$ & $1.93 \pm$ & $28.78 \pm$ & $43.17 \pm$ & $2.63 \pm$ & $28.58 \pm$ & $42.97 \pm$ & $2.83 \pm$ \\
& 0.86 & 2.18 & 1.12 & 0.16 & 1.48 & 1.82 & 0.04 & 1.28 & 2.02 \\
\hline \multirow{3}{*}{ Monsoon } & $29.33 \pm$ & $73.36 \pm$ & $13.66 \pm$ & $28.63 \pm$ & $72.66 \pm$ & $14.36 \pm$ & $28.43 \pm$ & $72.46 \pm$ & $14.56 \pm$ \\
& 0.26 & 1.45 & 4.33 & 0.44 & 0.75 & 5.03 & 0.64 & 0.55 & 5.23 \\
\hline
\end{tabular}

\section{Study design: pilot study}

To proceed with the evaluation of butterfly species associated with plants, a pilot survey was carried out for a period of 6 consecutive weeks along transect in selected sites. For each site, there were three transect paths ( $1000 \mathrm{~m}$ each) in $500 \mathrm{~m}$ gap. The sampling of plants and butterfly species was made in the study units (quadrat of $5 \times 5 \mathrm{~m} ; \mathrm{n}=45$ ) along each transect $(n=3)$ from the three different sites (urban, suburban and rural). Within $5 \mathrm{~m}$ to either side of each transects, five quadrats of $5 \times 5 \mathrm{~m}$ were established using poles and ropes. In each sampling site, the butterflies were recorded following 'Pollard Walk' method (Pollard, 1977; Pollard, Yates, 1993) with required modifications. During preliminary study, each species of flowering plants was recorded from each quadrat. The plants were recorded only when butterflies were sitting on the plants either for sucking nectar or laying eggs. The relative ability of the plant species to host the butterflies was measured through an index of butterfly load, using the formula stated below:

Butterfly load $=\mathrm{P}_{\mathrm{b}} / \mathrm{P}_{\mathrm{i}}$

where, $\mathrm{P}_{\mathrm{b}}$ is the proportion of the total butterfly species and $\mathrm{P}_{\mathrm{i}}$ is the proportion of the ith plant species.

For the butterfly species, the relative preference for the plant species was also assessed through the proportion presence in the plants.

Preference $=\mathrm{B}_{\mathrm{i}} / \mathrm{P}_{\mathrm{i}}$

where, $\mathrm{B}_{\mathrm{i}}$ is the proportion of the ith butterfly species in the plant and $\mathrm{P}_{\mathrm{i}}$ is the proportion of the ith plant species. For both the estimates (butterfly load and preference), a two-tailed t-test was conducted to deduce the deviation from unity. The assumptions are that the butterfly load and the preference should be proportional to the available plant numbers in the sampling units.

The butterfly load in the plants was used as an indicator to evaluate the species specific differences in hosting butterflies. Disparity in the resource quality of the plants is expected to manifest as a difference in the relative butterfly load of the plants. Thus, a proximate level assessment of the resource value of the plants is being reflected through the butterfly load value. The quadrat within a sampling space was heterogeneous in species composition and abundance of the plants and thus, the proportional values were considered instead of the original numbers encountered. 
The preference of host plants by the butterflies was judged through the relative abundance in the plants within unit space. In absence of any preference, the possibility of encountering a butterfly species in the plants remains same irrespective of the sites and the constituent species. Any deviation from uniform association of the butterflies with the plants will be an indicator of its relative preference, at least in the proximate level. Thus, the proportional representations of the plants and the butterflies were used to estimate the preference indication by butterfly species. The indicator is, however, not a complete reflection of the quantitative factors that guide the preference pattern of the butterflies.

In the pilot study, 25 different species of butterflies were encountered with different relative abundance of which 10 species were noted to be present consistently throughout the pilot study. Out of the 25 species, 10 species of butterflies were noted to choose Lantana as their food (nectar) source frequently in all selected study sites. Thus, the 10 species of butterflies belonging to the families Papilionidae, Pieridae and Nymphalidae were considered for the present study as depicted in Fig. 1. Although, rest of the 15 species was encountered inconsistently in subsequent observations, the continuous observation was restricted to the analysis of 10 species of butterfly only.

\section{Sampling techniques: continuous observations}

The continuous observations on the butterfly species were initiated using L. camara as a focal species in randomly selected bushes from three different sites (urban, suburban and rural) within the same study area as that of the pilot study. For each site, there were three transect paths (1000 m each) in $500 \mathrm{~m}$ gap. The sampling of plants and butterfly species was made in the study units (quadrat of $5 \times 5 \mathrm{~m}$ ) along each transect $(\mathrm{n}=3)$. In the initial phase, the bushes were segregated on the basis of presence and absence of L. camara in all the sites. The data on the richness and abundance of the butterflies in these bushes were collected and compared (30 quadrats each) for the difference, if any to further substantiate the findings of the pilot study. Although, the observations of the bushes without L. camara did not sufficiently represent control groups, still the difference in the richness and abundance of butterfly could be inferred at a spatial scale. In addition, the bushes with and without L. camara differed considerably in terms of species composition and the area covered. In course of the continuous survey, the bushes without L. camara did not expand in size (area and species composition and abundance) in comparison with bushes with L. camara, possibly a reflection of the features of invasive species. To notice the pattern of association of 10 selected butterflies, five $L$. camara plants were chosen randomly along each transect path at $200 \mathrm{~m}$ intervals $(200 \times 5=1000 \mathrm{~m})$ and marked for the entire study (Fig. 2). A total of 15 (3 transects x 5 plants) plants were chosen from each site (urban, suburban and rural) for a sampling day. The choice of the individual plants for the present study was done following Bloch et al. (2006) with necessary modifications. Individual plants in each site was sampled at an interval of 30 days (monthly) during October 2011 to September 2012; each site was visited on a fixed date in a month
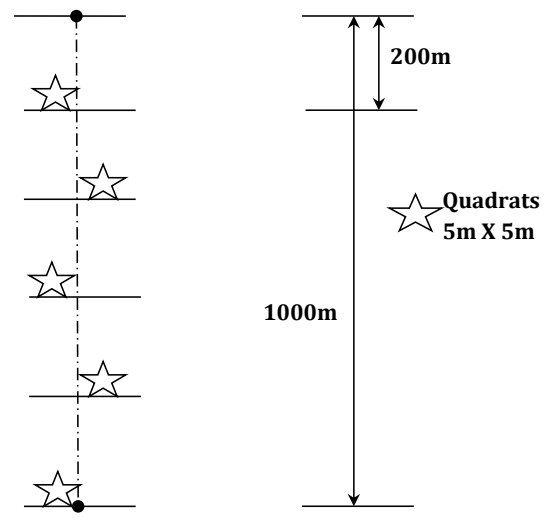

Fig. 2. Diagram of sampling plots for Lantana camara along each transect at each site. and twice in a day (morning, evening) and this continued for the total study period (Yeargan, Colvin, 2009). Each single plant was observed for $15 \mathrm{~min}$ and among all flower visitors, only the 10 selected butterflies were recorded. Thus, the total number of selected butterflies comprised the data recorded both in the morning and afternoon period. The number of flower clusters or inflorescence and selected butterfly species from selected individual plant from each site were recorded for each respective month. Evidences of direct sighting/viewing rather than collection of live specimen of butterflies were emphasised and digital photos (using Canon ${ }^{\circ}$ EOS 350D) were taken in every incident. On some rare occasions where direct viewing were hindered due to poor visibility, wind velocity or available light conditions, butterflies were sampled using a hand net (mesh size $100 \mu \mathrm{m}$ ) following Tiple (2012). Following identification using suitable keys (Haribal, 1992; Kunte, 2000; Kehimkar, 
2008) and record on the data, the butterfly specimens caught were released in the same habitat from where they were captured without disturbing the biological integrity. Enough care was taken to ensure that the scales of the butterfly wings were minimally affected. In all instances, both for the pilot study and the continuous study, all the sampling sites included bushes occurring naturally. Under no condition, any artificially managed bushes were considered.

\section{Data analysis}

Variation in the butterfly abundance in the three sites, urban, suburban and rural, was assessed in conjunction with the density of flowers of L. camara. Data on number of flowers were categorised as low (1-5), medium low (6-9), medium high (10-15), high low (16-24), high medium (25-70). In order to deduce the dependency of the butterflies on the flower density of L. camara, a generalised linear model (GLM) was assumed with the sites and flower density as explanatory variables. Assuming GLM, the data on the relative abundance of each butterfly species was subjected to a regression following binomial GLM using a logit link with flower density and sites as predictors. In the binomial GLM, the response variable 'proportion of butterfly species' was assumed to follow binomial (n, p) distribution with $\mathrm{n}$ trials (collection samples within a quadrat) for each combination of explanatory variables. The probability parameter $\mathrm{p}$ is here a linear combination of explanatory variables. A logit link was used and parameters were estimated through maximum likelihood using the software XLSTAT (Addinsoft, 2010). A Chi-square value was used to deduce the significance of the estimated parameters of the model that includes flower density and sites. To comment on the variation with respect to site and time, data on butterfly abundance was subjected to a three-way factorial analysis of variance ANOVA considering sampling sites, time and butterfly species as variables. Further, to infer on difference in abundance of butterfly species along the urbanisation gradient, data on relative abundance was subjected to a two-way factorial ANOVA, considering sites-months and number of flowers-months as variables. Further, the data on flower density and respective butterfly abundance were log $(n+1)$ transformed and subjected to Discriminant function analysis (DA). In DA, data on selected butterfly species were only recorded during the course of the study period; other butterflies and insects, though encountered during the study, were excluded from the data analysis. The statistical analyses (Legendre, Legendre, 1998; Zar, 1999) were performed using the SPSS ver.10 (Kinnear, Gray, 2000) and XLSTAT software (Addinsoft, 2010).

\section{Results}

The results of the pilot study revealed the presence of $L$. camara in each sampling unit (a quadrat) with varying numbers depending on the sites (Fig. 3). In each quadrat, on an average $3.5 \pm 0.27 \mathrm{SE}$, L camara (LCA) were observed along with varying numbers of plant species like, Cestrum diurnum L. (CDI), Catharanthus roseus L. (CRO), Ixora coccinea L. (ICO), Flacourtia indica (Burm. f.) Merr (FIN), Sida rhombifolia L. (SRH), Crotalaria pallida Ait. (CPA), Tridax procumbens L. (TPR), Ageratum conyzoides L. (ACO), Parthenium hysterophorus L. (PHY), Cleome rutidosperma DC. (CRU), Cleome viscosa L. (CVI), Leucas aspera (Willd) Link (LAS), Clerodendrum viscosum Vent. (CVS) and Vernonia cinerea L. (VCI). Although, the relative abundance of the individual plant species varied in the quadrats $\left(\mathrm{F}_{14,600}=10.74 \mathrm{P}<0.001\right)$, no significant difference was observed among the plant species assemblages $\left(\mathrm{F}_{4,600}=1.13 ; \mathrm{P}>0.05\right)$, indicating homogeneity of the sampling units (qaudrats). Irrespective of the sites, the number of transects varied significantly $\left(\mathrm{F}_{8,540}=10.52, \mathrm{P}<0.001\right)$ in terms of plant species composition and relative abundance of plant species as well $\left(\mathrm{F}_{14,540}\right.$ $=8.71, \mathrm{P}<0.001)$. The results are indicative of differences in the plant species composition in the three sites (rural, suburban and urban) when transects are considered as units of study, but not among the quadrats. The correspondence of the relative load of butterflies and the relative abundance was evident for the plant species (Fig. 3). Both the abundance and the relative load of butterflies were highest for L. camara, thereby justifying its consideration 


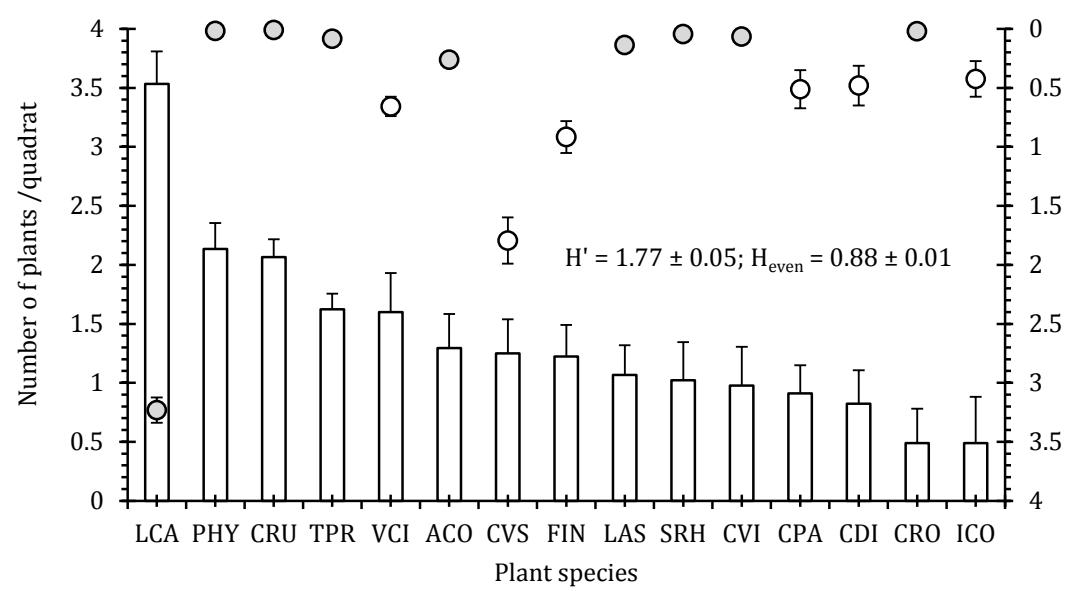

Fig. 3. The relative number (mean \pm SE) of plant species along with the proportional relative load of butterfly species (circles) observed in the study site. The mean value of the Shannon -Weiner diversity index and evenness value is provided for 45 quadrats. The shaded circles represent significant deviation from a value of 1 , as observed though two-tailed t-test with $\mathrm{df} 44$.

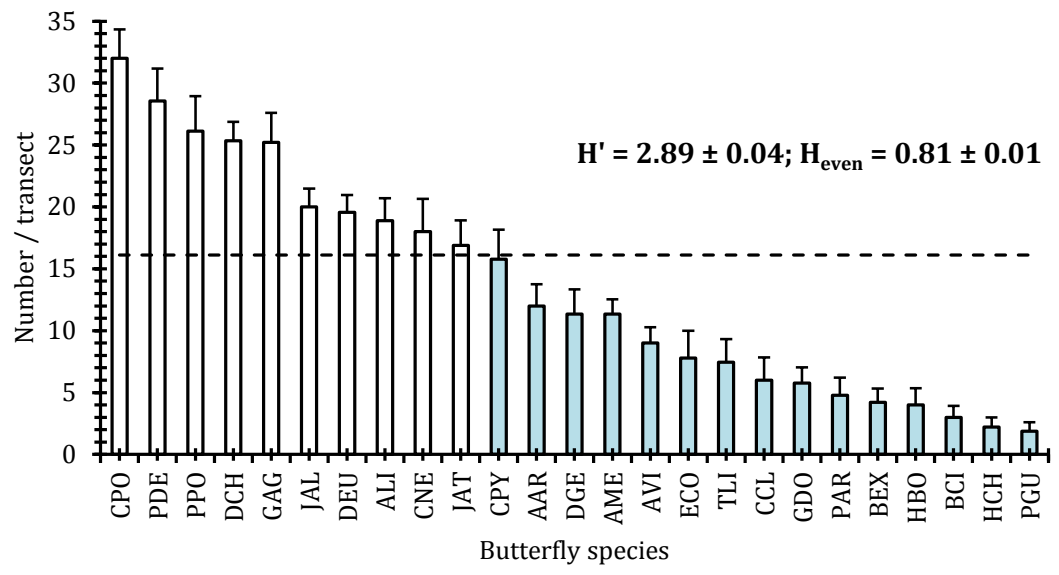

Fig. 4. The mean number of butterfly species encountered in the initiation of the study from nine transects spanning from urban to rural sites. The Shannon-Weiner diversity index and the evenness values are provided.

as a focal species for the study. The butterfly species observed in the study were Graphium doson (GDO), Graphium agamemnon (GAG), Chilasa clytia (CCL), Papilio polytes (PPO), Papilio demoleus (PDE), Catopsilia pomona (CPO), Pachliopta aristolochiae (PAR), Catopsilia pyranthe (CPY), Appias libythea (ALI), Cepora nerissa (CNE), Delias eucharis (DEU), Tirumala limniace (TLI), Danaus genutia (DGE), Danaus chrysippus (DCH), Euploea core (ECO), Acraea violae (AVI), Ariadne ariadne (AAR), Ariadne merione (AME), Junonia alma- 


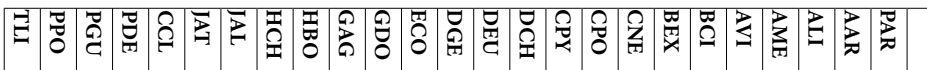

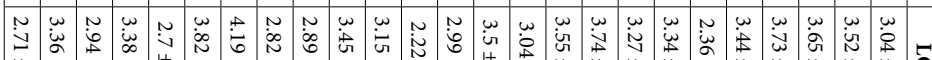

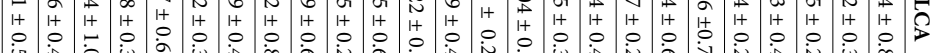
定

\begin{tabular}{|c|c|c|c|c|c|c|c|c|c|c|c|c|c|c|c|c|c|c|c|c|c|c|c|c|c|}
\hline ' & 1 & ' & $\begin{array}{l}0 \\
i \\
w \\
1+ \\
0 \\
i \\
w \\
w\end{array}$ & ' & 1 & 1 & 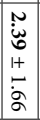 & $\begin{array}{l}0 \\
\text { UI } \\
1+ \\
0 \\
i \\
0\end{array}$ & 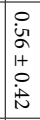 & ' & ' & 1 & 1 & 1 & ' & $\begin{array}{c}0 \\
\dot{\omega} \\
+1+ \\
0 \\
\dot{\omega} \\
\omega\end{array}$ & , & 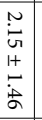 & $\begin{array}{l}u \\
\dot{\alpha} \\
1+ \\
\omega \\
\dot{\infty} \\
\infty\end{array}$ & ' & : & ' & ' & ' & $\theta$ \\
\hline ' & 1 & ' & $\begin{array}{l}0 \\
\dot{v} \\
1+ \\
0 \\
\dot{G}\end{array}$ & ' & 1 & 1 & ' & 1 & ' & ' & ' & 1 & 1 & ' & $\begin{array}{l}0 \\
\stackrel{0}{\omega} \\
1+ \\
0 \\
\dot{\omega}\end{array}$ & $\begin{array}{l}0 \\
i \sigma \\
1+ \\
0 \\
i= \\
\omega\end{array}$ & 1 & 1 & ' & ' & 1 & ' & ' & ' & $\widetilde{\sigma}$ \\
\hline ' & 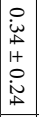 & ' & $\begin{array}{l}0 \\
i \in \\
i t \\
1+ \\
0 \\
i \omega \\
N\end{array}$ & 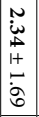 & 1 & 1 & ' & 1 & $\begin{array}{l}\text { i } \\
\text { N } \\
1+ \\
0 \\
\text { O }\end{array}$ & $\begin{array}{l}w \\
i v \\
1+ \\
N \\
v \\
v\end{array}$ & ' & 1 & 1 & 1 & ' & 1 & ' & 1 & ' & ' & 1 & ' & ' & $\begin{array}{l}\mathfrak{N} \\
\dot{\alpha} \\
1+ \\
N \\
\tilde{N} \\
v\end{array}$ & $\overline{0}$ \\
\hline $\begin{array}{l}\text { O } \\
\text { 怘 } \\
\text { It } \\
0 \\
\text { 岕 }\end{array}$ & $\begin{array}{l}N \\
\tilde{N} \\
1+ \\
\sim \\
0 \\
\end{array}$ & ' & $\begin{array}{l}\underset{\infty}{\infty} \\
w \\
1+ \\
0 \\
\dot{6} \\
\end{array}$ & 1 & 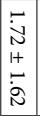 & \begin{tabular}{|l|}
0 \\
$i$ \\
$w$ \\
$1+$ \\
0 \\
$\underset{N}{N}$ \\
\end{tabular} & ' & $\begin{array}{l}0 \\
\text { in } \\
1+ \\
0 \\
i\end{array}$ & $\begin{array}{l}0 \\
\dot{0} \\
\infty \\
1+ \\
0 \\
\text { if }\end{array}$ & $\begin{array}{l}0 \\
\omega \\
1+ \\
0 \\
\omega\end{array}$ & $\begin{array}{l}0 \\
\dot{\omega} \\
i \\
1+ \\
0 \\
\underset{\perp}{+}\end{array}$ & $\begin{array}{l}0 \\
\text { in } \\
1+ \\
0 \\
i \sim j \\
N\end{array}$ & $\begin{array}{l}0 \\
i b \\
1+ \\
1+ \\
0 \\
i 1 \\
1\end{array}$ & 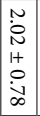 & 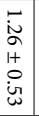 & \begin{tabular}{|c|} 
\\
0 \\
$\infty$ \\
$\infty$ \\
$1+$ \\
0 \\
Чू \\
\end{tabular} & $\begin{array}{l}N \\
\mathfrak{U} \\
\infty \\
1+ \\
-= \\
=\end{array}$ & 1 & ' & \begin{tabular}{|c|} 
\\
$\infty$ \\
$\omega$ \\
$1+$ \\
0 \\
$\infty$ \\
$\infty$
\end{tabular} & \begin{tabular}{|c|}
0 \\
$o \infty$ \\
$o$ \\
$1+$ \\
0 \\
ing \\
\end{tabular} & 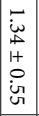 & 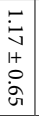 & 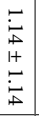 & Z \\
\hline ' & 1 & ' & ' & 1 & 1 & 1 & ' & 1 & ' & ' & $\begin{array}{l}0 \\
\text { N } \\
\text { It } \\
0 \\
\text { N } \\
\text { U }\end{array}$ & 1 & 1 & 1 & $\begin{array}{l}0 \\
\text { i } \\
1+ \\
0 \\
\text { i }\end{array}$ & $\begin{array}{l}0 \\
0 \\
\text { U } \\
1+ \\
0 \\
0 \\
\text { ज }\end{array}$ & ' & 1 & ' & 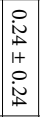 & \begin{tabular}{|l|}
0 \\
N \\
$1+$ \\
0 \\
N \\
\end{tabular} & ' & $\begin{array}{l}0 \\
\stackrel{5}{+} \\
1+ \\
0 \\
\dot{5}\end{array}$ & 1 & 总 \\
\hline 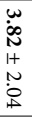 & 1 & ' & 1 & 1 & 1 & 1 & 1 & 1 & ' & ' & 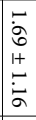 & $\begin{array}{l}\omega \\
\omega \\
N \\
1+ \\
- \\
\infty \\
+ \\
\end{array}$ & \begin{tabular}{|l|}
0 \\
0 \\
U \\
$1+$ \\
0 \\
0 \\
U \\
\end{tabular} & \begin{tabular}{|l|}
$w$ \\
$\tilde{N}$ \\
$I+$ \\
$N$ \\
$N$ \\
$\sim$ \\
$\sim$ \\
\end{tabular} & 1 & 1 & ' & 1 & ' & 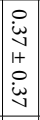 & \begin{tabular}{|l|}
0 \\
0 \\
0 \\
$1+$ \\
0 \\
0 \\
0 \\
\end{tabular} & ' & $\begin{array}{l}\circ \\
\dot{\sigma} \\
1+ \\
0 \\
\dot{\sigma} \\
\sigma\end{array}$ & ' & 8 \\
\hline ' & 1 & 1 & ' & 1 & 1 & 1 & ' & 1 & ' & ' & ' & 1 & 1 & $\begin{array}{c} \\
i \\
v \\
1+ \\
0 \\
i \\
v \\
\end{array}$ & $\begin{array}{l}0 \\
i \infty \\
i \\
1+ \\
0 \\
i \\
\sim \\
\sim\end{array}$ & 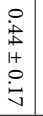 & $\begin{array}{l}0 \\
0 \\
0 \\
1+ \\
0 \\
0 \\
\text { N }\end{array}$ & 1 & ' & \begin{tabular}{|c|}
0 \\
$\dot{w}$ \\
It \\
0 \\
$\dot{w}$ \\
v
\end{tabular} & 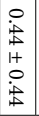 & ' & $\begin{array}{l}0 \\
\dot{\sigma} \\
1+ \\
0 \\
\dot{\sigma}\end{array}$ & 1 & 훙 \\
\hline ' & \begin{tabular}{|c|}
0 \\
$\dot{w}$ \\
$1+$ \\
0 \\
$i \sim$ \\
$\sim$
\end{tabular} & 1 & 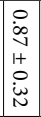 & 1 & \begin{tabular}{|l|}
0 \\
0 \\
$\omega$ \\
$1+$ \\
0 \\
0 \\
$\dot{\omega}$
\end{tabular} & 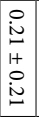 & 1 & 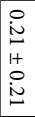 & $\begin{array}{l}0 \\
\dot{\infty} \\
\stackrel{\omega}{ } \\
1+ \\
0 \\
\dot{N} \\
\infty\end{array}$ & $\begin{array}{l}0 \\
\text { v } \\
1+ \\
0 \\
\text { v }\end{array}$ & $\begin{array}{l}0 \\
i \overrightarrow{6} \\
1+ \\
0 \\
\dot{0}\end{array}$ & $\begin{array}{l}0 \\
i v \\
1+ \\
0 \\
i v \\
v\end{array}$ & $\begin{array}{l}0 \\
i \\
i \\
1+ \\
0 \\
i \\
i t\end{array}$ & \begin{tabular}{|l|}
0 \\
$\dot{2}$ \\
$1+$ \\
0 \\
iv \\
\end{tabular} & $\begin{array}{l}0 \\
\stackrel{0}{w} \\
w \\
1+ \\
0 \\
\dot{\omega} \\
\text { v }\end{array}$ & $\begin{array}{l}0 \\
i \mathfrak{v} \\
1+ \\
0 \\
i=\end{array}$ & $\begin{array}{l}0 \\
\text { i } \\
1+ \\
0 \\
i= \\
\text { a }\end{array}$ & 1 & ' & ' & \begin{tabular}{|l|}
0 \\
0 \\
$\infty$ \\
$1+$ \\
0 \\
0 \\
$\infty$ \\
\end{tabular} & $\begin{array}{l}0 \\
\text { N } \\
1+ \\
0 \\
i \\
\text { a }\end{array}$ & 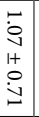 & ' & 8 \\
\hline ' & 1 & 1 & ' & 1 & 1 & 1 & ' & 1 & ' & ' & ' & 1 & 1 & $\begin{array}{c}0 \\
i \\
1+ \\
0 \\
i\end{array}$ & $\begin{array}{l}0 \\
\dot{\ddots} \\
+ \\
0 \\
\bullet\end{array}$ & $\begin{array}{l}0 \\
0 \\
0 \\
1 \\
1+ \\
0 \\
\dot{0} \\
\dot{y}\end{array}$ & ' & 1 & ' & ' & 1 & ' & 1 & 1 & $\vec{z}$ \\
\hline ' & 1 & 1 & ' & ' & 1 & 1 & 1 & 1 & ' & ' & $\begin{array}{l}0 \\
\dot{0} \\
\infty \\
1+ \\
0 \\
0 \\
\infty\end{array}$ & 1 & 1 & \begin{tabular}{|l|}
0 \\
0 \\
0 \\
$1+$ \\
0 \\
0 \\
0 \\
\end{tabular} & ' & $\begin{array}{l}\circ \\
\dot{8} \\
1+ \\
\circ \\
\dot{8}\end{array}$ & ' & 1 & ' & ' & 1 & \begin{tabular}{|c|} 
\\
0 \\
0 \\
U \\
$1+$ \\
0 \\
.0 \\
0
\end{tabular} & ' & 1 & $\widetilde{\Omega}$ \\
\hline ' & \begin{tabular}{|c|}
0 \\
$i$ \\
$1+$ \\
$1+$ \\
0 \\
$i$ \\
\end{tabular} & 1 & 1 & 1 & \begin{tabular}{|c|}
0 \\
$i \infty$ \\
$\infty$ \\
$1+$ \\
0 \\
$i \infty$ \\
$\infty$ \\
\end{tabular} & 1 & 1 & 1 & ' & ' & ' & 1 & $\begin{array}{l}0 \\
\stackrel{0}{N} \\
1+ \\
0 \\
i v y \\
\text { N }\end{array}$ & \begin{tabular}{|c|} 
\\
$i$ \\
$v$ \\
$1+$ \\
0 \\
$ن$ \\
$V$
\end{tabular} & I & $\begin{array}{l}0 \\
\dot{w} \\
1+ \\
\stackrel{0}{0} \\
\stackrel{\sim}{\omega}\end{array}$ & ' & 1 & ' & ' & 1 & \begin{tabular}{|c|}
0 \\
$i$ \\
$\infty$ \\
$N$ \\
$1+$ \\
0 \\
0 \\
$\infty$ \\
\end{tabular} & ' & ' & 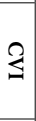 \\
\hline ' & 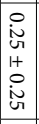 & 1 & 1 & \begin{tabular}{|c|}
0 \\
i \\
$N$ \\
$1+$ \\
0 \\
$i$ \\
$N$ \\
\end{tabular} & \begin{tabular}{|c|}
0 \\
$\dot{w}$ \\
It \\
0 \\
$\dot{w}$ \\
$v$ \\
\end{tabular} & 1 & 1 & 1 & $\begin{array}{l}0 \\
\text { un } \\
1+ \\
0 \\
\text { w } \\
\text { H }\end{array}$ & ' & ' & $\begin{array}{l}\cdot \vec{\sigma} \\
\sigma \\
1+ \\
\vdots \\
\dot{a}\end{array}$ & ' & \begin{tabular}{|l|}
0 \\
N \\
It \\
0 \\
0 \\
N \\
\end{tabular} & 1 & $\begin{array}{l}\stackrel{0}{0} \\
\stackrel{N}{N} \\
1+ \\
0 \\
\stackrel{N}{N}\end{array}$ & 1 & ' & ' & ' & 1 & \begin{tabular}{|c|}
0 \\
N \\
$1+$ \\
$1+$ \\
0 \\
N \\
$N$ \\
\end{tabular} & ' & ' & $\sum_{\infty}^{5}$ \\
\hline 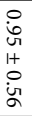 & $\begin{array}{l} \\
\dot{\sigma} \\
\tilde{1} \\
1+ \\
0 \\
\dot{0} \\
\end{array}$ & $\begin{array}{l}0 \\
\text { in } \\
1+ \\
0 \\
\text { in } \\
\mapsto\end{array}$ & $\begin{array}{l}\mid \vec{b} \\
\dot{0} \\
1+ \\
0 \\
\dot{\omega}\end{array}$ & $\begin{array}{l}0 \\
i 0 \\
N \\
1+ \\
0 \\
i v \\
\perp\end{array}$ & 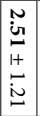 & 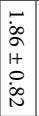 & $\begin{array}{l} \\
\dot{N} \\
N \\
1+ \\
0 \\
\stackrel{N}{N} \\
\end{array}$ & 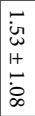 & 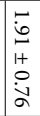 & $\begin{array}{l}N \\
\stackrel{N}{*} \\
1+ \\
\ddot{\circ} \\
\Omega\end{array}$ & 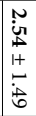 & $\begin{array}{l}N \\
i s \\
\text { in } \\
1+ \\
0 \\
\infty \\
\dot{v}\end{array}$ & $\begin{array}{l}N \\
i \vec{b} \\
1+ \\
\sim \\
w \\
\omega\end{array}$ & 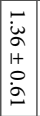 & 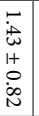 & 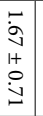 & 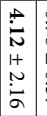 & 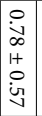 & ' & 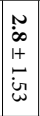 & 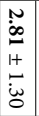 & 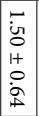 & 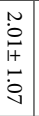 & \begin{tabular}{|c|}
-1 \\
0 \\
$1+$ \\
0 \\
$\infty$ \\
$+\infty$ \\
\end{tabular} & 趈 \\
\hline $\begin{array}{l}\stackrel{0}{\dot{\omega}} \\
\dot{\infty} \\
1+ \\
0 \\
\dot{\infty} \\
\infty\end{array}$ & \begin{tabular}{|c|}
0 \\
iv \\
$1+$ \\
0 \\
$i$ \\
v \\
\end{tabular} & $\begin{array}{l}0 \\
\text { in } \\
1+ \\
0 \\
\text { in }\end{array}$ & $\begin{array}{l}0 \\
\text { î } \\
1+ \\
0 \\
\text { N } \\
\end{array}$ & 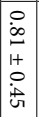 & 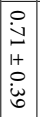 & \begin{tabular}{|l|} 
\\
0 \\
$\infty$ \\
$1+$ \\
0 \\
$i$ \\
0 \\
\end{tabular} & \begin{tabular}{|l|}
0 \\
$\dot{2}$ \\
$1+$ \\
0 \\
$\dot{2}$ \\
\end{tabular} & $\begin{array}{l}0 \\
\text { i̊ } \\
2 \\
1+ \\
0 \\
\stackrel{1}{+}\end{array}$ & 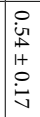 & $\begin{array}{l}0 \\
i \\
1+ \\
0 \\
i\end{array}$ & ' & $\begin{array}{l}0 \\
i \\
1+ \\
0 \\
i\end{array}$ & $\begin{array}{l}0 \\
i b \\
1 \\
1+ \\
0 \\
\dot{\omega} \\
0\end{array}$ & 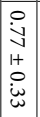 & $\begin{array}{l}0 \\
\text { b } \\
1+ \\
0 \\
\text { 岕 }\end{array}$ & $\begin{array}{l}0 \\
0 \\
0 \\
1+ \\
0 \\
i \mathfrak{v} \\
\text { un }\end{array}$ & $\begin{array}{l}0 \\
0 \\
1+ \\
1+ \\
0 \\
\omega \\
\omega\end{array}$ & $\begin{array}{l}-\underset{0}{0} \\
\text { w } \\
1+ \\
0 \\
\text { N } \\
\text { N }\end{array}$ & $\begin{array}{l}0 \\
\infty \\
\alpha \\
1+ \\
0 \\
\infty \\
\infty\end{array}$ & 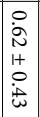 & \begin{tabular}{|c|}
0 \\
in \\
$N$ \\
$1+$ \\
0 \\
$\dot{w}$ \\
\end{tabular} & \begin{tabular}{|c|}
0 \\
N \\
$1+$ \\
0 \\
$\dot{\omega}$ \\
0 \\
\end{tabular} & $\begin{array}{l}\stackrel{0}{y} \\
w \\
1+ \\
0 \\
i \\
\infty\end{array}$ & $\begin{array}{l}0 \\
i \\
1+ \\
1+ \\
0 \\
\dot{\omega} \\
-\end{array}$ & 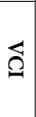 \\
\hline
\end{tabular}

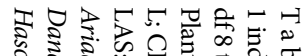

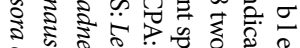

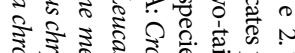

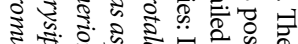

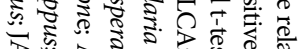

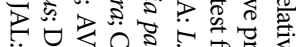

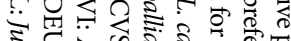
₹

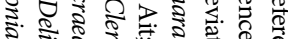

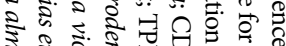

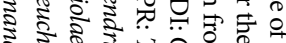

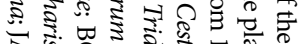

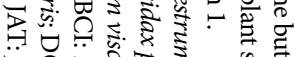

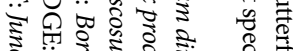

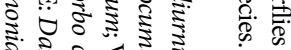

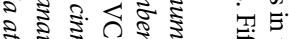

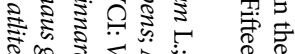
คิ 引. की

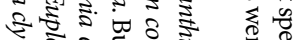

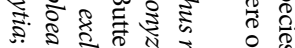

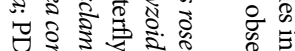

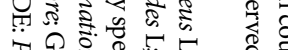

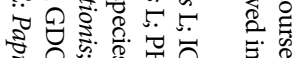
훙

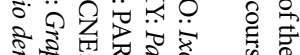

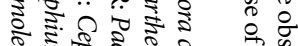

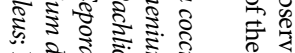

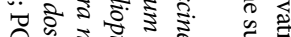
万़ि

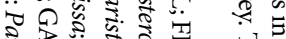

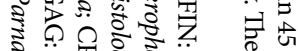

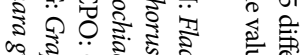

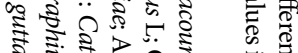

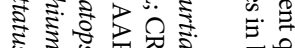

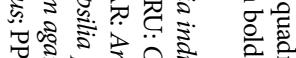

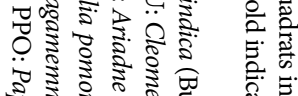
竎. 可

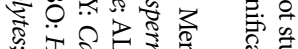

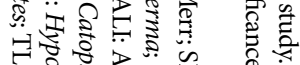

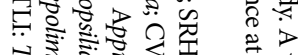

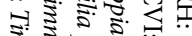
उ

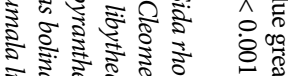
इ

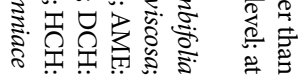



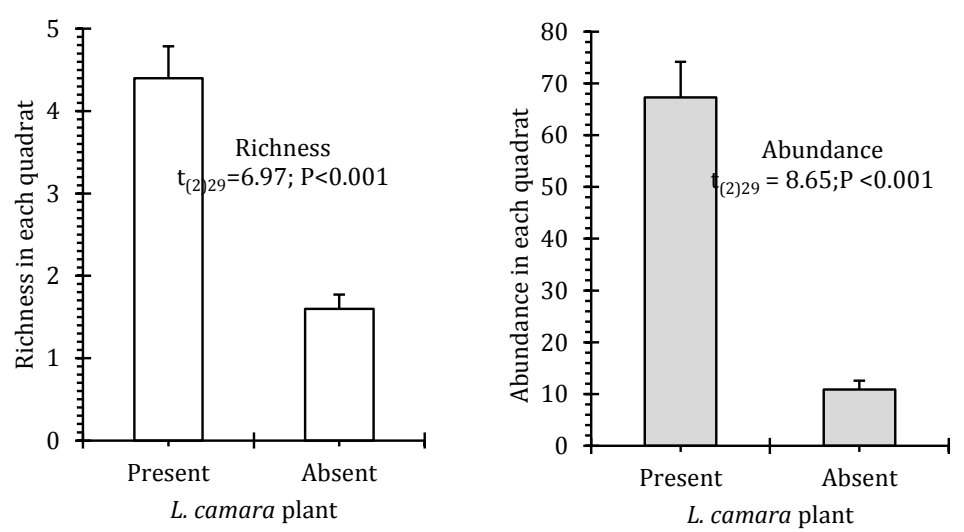

Fig. 5. The richness and abundance of butterflies in the quadrat with and without Lantana camara as observed in the pilot study.

$\mathrm{T}$ a ble 3. Variation in the peak flowering season, number of flowers and height of the Lantana camara. The number of flowers represents the average maximum and minimum observed from all the five plants as selected for the study.

\begin{tabular}{|l|c|c|c|c|}
\hline Spot & Peak Flowering season & Flower's number Range & Flower's number Mean & Height (m) \\
\hline Urban & July-Sept & $17-124$ & $63.92 \pm 9.28$ & $1.24 \pm 0.14$ \\
\hline Suburban & Aug-Sept & $29-160$ & $82.33 \pm 12.43$ & $1.37 \pm 0.12$ \\
\hline Rural & Sept-Oct & $37-179$ & $90.08 \pm 12.71$ & $1.4 \pm 0.58$ \\
\hline
\end{tabular}

na (JAL), Junonia atlites (JAT), Hypolimnas bolina (HBO), Borbo cinnara (BCI), Parnara guttatus (PGU), Badamia exclamationis (BEX), Hasora chromus (HCH). Significant differences were observed among the butterfly species in transects $\left(\mathrm{F}_{24,200}=24.889 ; \mathrm{P}<0.001\right)$ reflecting the heterogeneity of species composition in the individual L. camara plant. The data on each quadrat from a particular transect was pooled together and the mean value was assessed. This is substantiated by the Shannon-Weiner diversity indices of butterfly species in the survey (Fig. 4). The relative preference of the butterflies in the different plant species were observed in course of the observations in 45 different quadrats in the pilot study (Table 2). Among the different plant species, the butterflies exhibited significantly higher $(\mathrm{P}<0.05)$ preference for L. camara over all other plants. Although, in course of the sampling of the L. camara across the sites (urban, suburban and rural), different butterflies were encountered inconsistently that prevented them from their inclusion in the subsequent studies. In continuation with the pilot study, the abundance and species richness of the butterflies were compared in the presence and absence of $L$. camara among different quadrats and the results significantly differed (Fig. 5). The selection of the butterfly species for further observations was based on the relative numbers available in this pilot survey. Using the 10 most abundant butterfly species (Fig. 1), the observations and analysis were made with respect to the butterfly density and the flowering nature of $L$. camara in the sites. The relative number of flowers and the peak flower- 


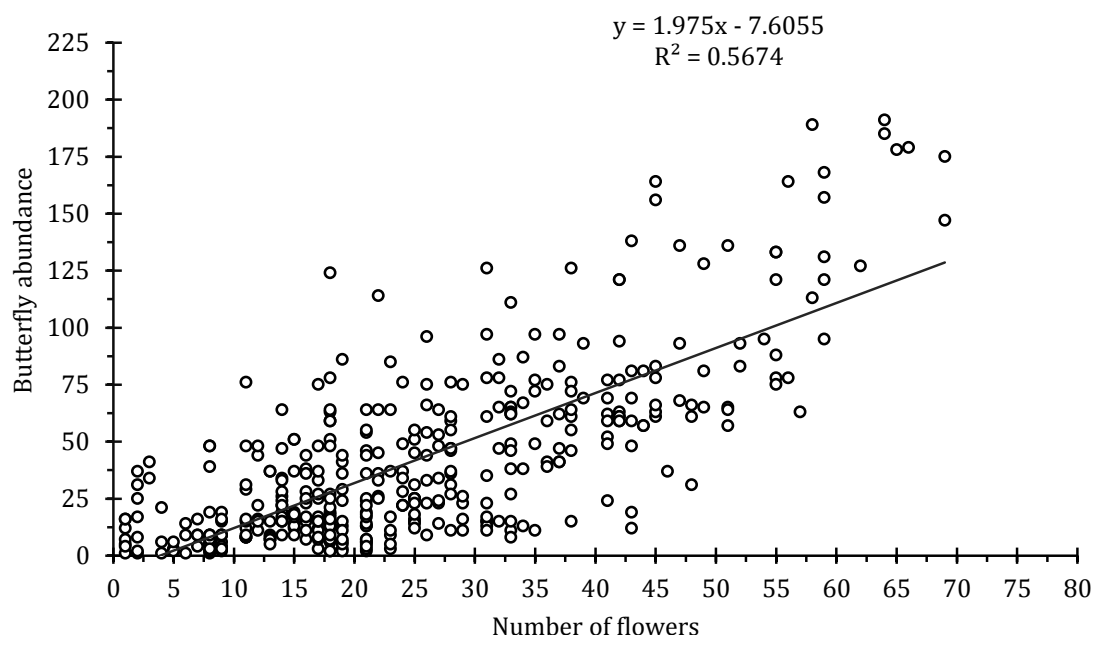

Fig. 6. The correlation of the total butterfly abundance with the density of the flowers of Lantana camara observed through transects in all the sites. An increase in abundance is associated with the increase in the flower density of the plant in transects sampled during the study period. Plant samples without flowers were not considered, though these were positive for the presence of the butterflies.

$\mathrm{T} \mathrm{a} \mathrm{b} \mathrm{l} \mathrm{e} \mathrm{4.} \mathrm{The} \mathrm{parameters} \mathrm{for} \mathrm{identification} \mathrm{of} \mathrm{the} \mathrm{flower} \mathrm{density} \mathrm{of} \mathrm{Lantana} \mathrm{camara} \mathrm{and} \mathrm{the} \mathrm{sites} \mathrm{as} \mathrm{explanatory}$ factors for the observed abundance of the butterfly species. The equation being Abundance $=1 /\left(1+\exp \left(-\left(a+b_{1} x_{1}\right.\right.\right.$ $\left.\left.-\mathrm{b}_{2} \mathrm{x}_{2}\right)\right)$ ). The values in bold indicate significance at $\mathrm{P}<0.05$ level as perWald's Chi-square following the logistic regression model.

\begin{tabular}{|l|c|c|c|}
\hline Butterfly & Intercept & Site & Flower density \\
\hline Graphium agamemnon & $-3.12 \pm 0.17$ & $-0.04 \pm 0.03$ & $\mathbf{0 . 2 4} \pm \mathbf{0 . 0 3}$ \\
\hline Papilio polytes & $-2.12 \pm 0.14$ & $0.03 \pm 0.03$ & $0.02 \pm 0.03$ \\
\hline Papilio demoleus & $-2.23 \pm 0.15$ & $-\mathbf{0 . 0 7} \pm \mathbf{0 . 0 3}$ & $-0.05 \pm 0.03$ \\
\hline Danaus chrysippus & $-2.07 \pm 0.15$ & $-0.03 \pm 0.03$ & $-0.05 \pm 0.03$ \\
\hline Junonia atlites & $-1.49 \pm 0.13$ & $-0.04 \pm 0.03$ & $-\mathbf{0 . 1 1} \pm \mathbf{0 . 0 3}$ \\
\hline Catopsilia pomona & $-2.49 \pm 0.17$ & $-0.01 \pm 0.05$ & $0.05 \pm 0.03$ \\
\hline Appias libythea & $-2.57 \pm 0.17$ & $0.05 \pm 0.04$ & $-0.0 \pm 0.04$ \\
\hline Cepora nerissa & $-2.70 \pm 0.20$ & $0.04 \pm 0.05$ & $-0.07 \pm 0.04$ \\
\hline Junonia almana & $-1.36 \pm 0.12$ & $-0.03 \pm 0.02$ & $-0.02 \pm 0.02$ \\
\hline Delias eucharis & $-2.54 \pm 0.16$ & $\mathbf{0 . 1 9} \pm \mathbf{0 . 0 4}$ & $\mathbf{- 0 . 0 8} \pm \mathbf{0 . 0 3}$ \\
\hline
\end{tabular}

ing time of L. camara varied with the sampling sites (Table 3). A positive correlation was observed between the flower density and the overall density of butterflies in each sampling unit irrespective of the sites (Fig. 6). The GLM analysis using logit link binomial functions suggested that the flower density significantly influenced the relative distribution of at least four butterfly species while for two butterfly species, the sites influenced the abundance pattern (Table 4). The relative abundance (mean \pm SE) of butterflies recorded during morning and afternoon varied significantly (Table 5) reflecting a prospective diurnal variations in the activities of the butterflies. The number of flowers 
T a b l e 5. Relative abundance (mean \pm SE) of butterflies recorded during morning and afternoon. The data represented the abundance irrespective of season. All the t-values are significantly different at $\mathrm{P}<0.001$ level. $\mathrm{df}-107$.

\begin{tabular}{|l|c|c|c|}
\hline Butterfly & Morning & Evening & t-value \\
\hline Graphium agamemnon & $26.92 \pm 6.84$ & $9.58 \pm 2.92$ & 2.99 \\
\hline Papilio polytes & $30.25 \pm 5.63$ & $11.75 \pm 2.48$ & 3.36 \\
\hline Papilio demoleus & $27.67 \pm 5.28$ & $11.58 \pm 2.90$ & 3.07 \\
\hline Danaus chrysippus & $24.33 \pm 4.75$ & $10.00 \pm 2.50$ & 2.70 \\
\hline Junonia atlites & $31.00 \pm 5.00$ & $13.00 \pm 2.75$ & 3.44 \\
\hline Catopsilia pomona & $26.50 \pm 5.02$ & $11.25 \pm 2.87$ & 2.94 \\
\hline Appias libythea & $22.83 \pm 4.55$ & $8.75 \pm 2.19$ & 2.54 \\
\hline Cepora nerissa & $15.50 \pm 2.32$ & $4.17 \pm 1.14$ & 1.72 \\
\hline Junonia almana & $51.50 \pm 8.84$ & $22.42 \pm 4.26$ & 5.72 \\
\hline Delias eucharis & $24.83 \pm 4.50$ & $8.58 \pm 1.90$ & 2.76 \\
\hline
\end{tabular}

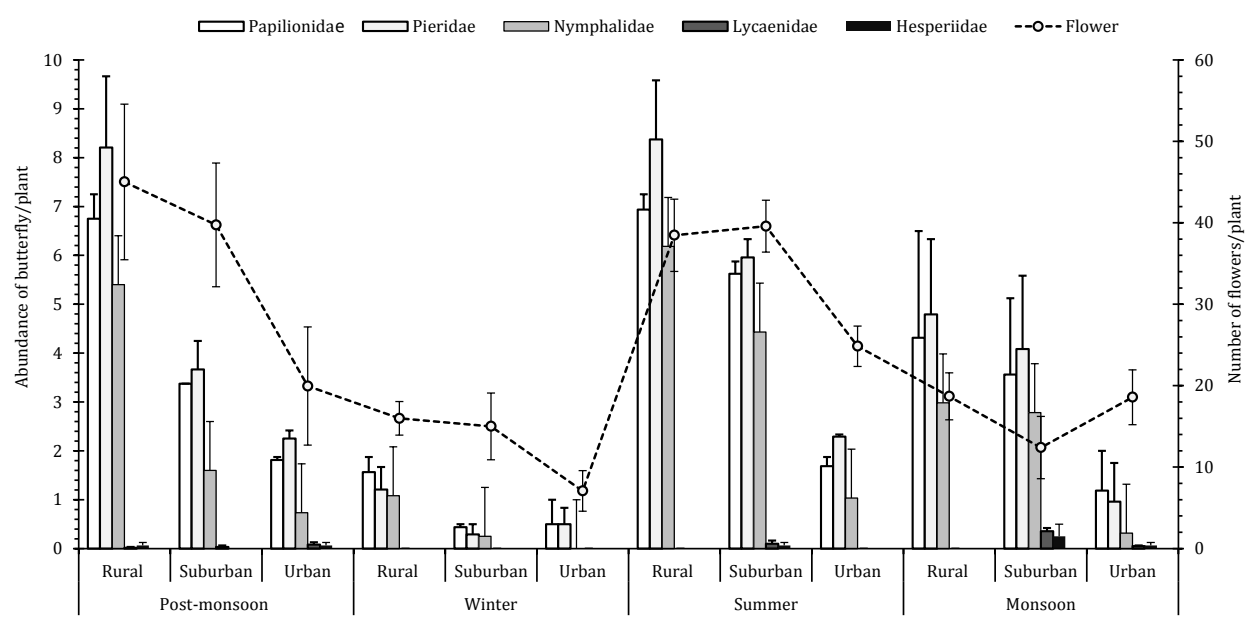

Fig. 7. Seasonal variation in occurrence of butterflies along with Lantana camara flowering observed in three different sites during the survey period (October 2011-September 2012).

produced by the Lantana plants and occurrence of butterfly species varied with months showing its bloom in the summer and post-monsoon months and a sharp decline was observed at the onset of winter (December) and mid-monsoon (July) (Fig. 7). The occurrence of the butterflies showed a peak during the summer (March-May) and post monsoon (September-November) months and decreased during the winter and mid-monsoon in accordance with the number of blooms (Fig. 7).The results of the three-way factorial ANOVA reflected that the abundance of butterflies varied significantly with the sampling site as well as with the time of sampling (Table 6 and Fig. 8). However, the interaction between sampling site and butterfly species and that between sampling site, time and species did not vary significantly, possibly due to independent variation 
T a b l e 6. Results of three-way factorial ANOVA on the abundance of butterflies considering sampling sites, time and species as explanatory variables. F-values marked in bold are significant at $\mathrm{P}<0.05$ level.

\begin{tabular}{|c|c|c|c|c|c|}
\hline Sources of variation & Sum of squares & df & Mean square & $\mathbf{F}$ & Partial $\eta^{2}$ \\
\hline Site (S) & 1607.101 & 2 & 803.550 & 198.716 & 0.159 \\
\hline Time (T) & 1932.337 & 1 & 1932.337 & 477.862 & 0.185 \\
\hline Butterfly (B) & 1161.467 & 9 & 129.052 & 31.914 & 0.120 \\
\hline $\mathrm{S}^{*} \mathrm{~T}$ & 201.619 & 2 & 100.810 & 24.930 & 0.023 \\
\hline$S^{*} B$ & 97.668 & 18 & 5.426 & 1.342 & 0.011 \\
\hline $\mathbf{T}^{\star} \mathbf{B}$ & 134.371 & 9 & 14.930 & 3.692 & 0.016 \\
\hline$S^{*} T^{\star} B$ & 14.575 & 18 & 0.810 & 0.200 & 0.002 \\
\hline Error & 8491.806 & 2100 & 4.044 & & \\
\hline Total & $13,640.944$ & 2159 & & & \\
\hline
\end{tabular}

$\mathrm{T}$ a b l e 7. Pearson correlation matrix between number of flowers and butterfly species, along with a multiple regression analysis to represent the relation of the flower density and the relative abundance of the 10 butterfly species. All values are significant at $\mathrm{P}<0.05$. FA - Flower abundance.

\begin{tabular}{|l|c|c|c|c|c|c|c|c|c|c|}
\hline Butterfly & FA(y) & GAG & PPO & PDE & DCH & JAT & CPO & ALI & CNE & JAL \\
\hline Graphium agamemnon & 0.712 & & & & & & & & & \\
\hline Papilio polytes & 0.714 & 0.807 & & & & & & & & \\
\hline Papilio demoleus & 0.738 & 0.763 & 0.867 & & & & & & & \\
\hline Danaus chrysippus & 0.667 & 0.69 & 0.818 & 0.85 & & & & & & \\
\hline Junonia atlites & 0.686 & 0.759 & 0.838 & 0.819 & 0.806 & & & & & \\
\hline Catopsilia pomona & 0.686 & 0.723 & 0.816 & 0.888 & 0.853 & 0.806 & & & & \\
\hline Appias libythea & 0.657 & 0.667 & 0.744 & 0.797 & 0.728 & 0.753 & 0.764 & & & \\
\hline Cepora nerissa & 0.557 & 0.626 & 0.681 & 0.735 & 0.695 & 0.709 & 0.664 & 0.645 & & \\
\hline Junonia almana & 0.697 & 0.784 & 0.834 & 0.818 & 0.768 & 0.827 & 0.805 & 0.761 & 0.645 & \\
\hline Delias eucharis & 0.561 & 0.649 & 0.743 & 0.722 & 0.761 & 0.714 & 0.729 & 0.684 & 0.662 & 0.734 \\
\hline
\end{tabular}

Flower no. $(\mathrm{y})=-0.477+12.868\left(\mathrm{X}_{1}\right)+2.788\left(\mathrm{X}_{2}\right)+14.209\left(\mathrm{X}_{3}\right)+4.112\left(\mathrm{X}_{4}\right)+2.605\left(\mathrm{X}_{5}\right)-0.179\left(\mathrm{X}_{6}\right)+6.75\left(\mathrm{X}_{7}\right)$ $-2.28\left(\mathrm{X}_{8}\right)+3.357\left(\mathrm{X}_{9}\right)-4.812\left(\mathrm{X}_{10}\right) \mathrm{F}=83.604 . \mathrm{P}<0.001, \mathrm{df}=10,528 ; \mathrm{R}^{2}=0.613, \mathrm{R}=0.78$, where $\mathrm{X}_{1}=\mathrm{GAG}_{2} \mathrm{X}_{2}=$ PPO, $X_{3}=$ PDE, $X_{4}=$ DCH, $X_{5}=J A T, X_{6}=C P O, X_{7}=A L I, X_{8}=C N E, X_{9}=J A L, X_{10}=$ DEU

of the variables (Zar, 1999). The results of the two-way factorial ANOVA revealed that the abundance of butterflies varied significantly with the months $\left(\mathrm{F}_{(1) 11,1044}=100.77, \mathrm{P}<0.05\right)$ and site $\left(\mathrm{F}_{(1)}\right.$ $\left.{ }_{2,1044}=222.83, \mathrm{P}<0.05\right)$ and the interaction between months and sites $\left(\mathrm{F}_{(1) 22,1044}=8.78, \mathrm{P}<0.05\right)$. The size effect (Partial $\eta 2=0.74$ ) was highest for site in contrast to months (Partial $\eta 2=0.63$ ), suggesting considerable heterogeneity in terms of observed abundance of butterfly species on $\mathrm{L}$. $\mathrm{ca}$ mara. Significant differences were also observed for the butterfly density with the number of flowers present per L. camara plant $\left(\mathrm{F}_{(1) 43,991}=10.72, \mathrm{P}<0.05\right)$ and with the months $\left(\mathrm{F}_{(1) 11,991}=12.01\right.$, $\mathrm{P}<0.05)$. The interaction between flower density and months was also significant $\left(\mathrm{F}_{(1) 34,991}=4.70\right.$, $\mathrm{P}<0.05)$ justifying the level of heterogeneity in flowering density per plant in different months. The size effect was highest for months (Partial $\eta 2=0.71$ ) followed by flower density (Partial $\eta 2=$ 0.62 ) and interaction (Partial $\eta 2=0.12$ ). The post hoc Tukey test revealed significant differences 

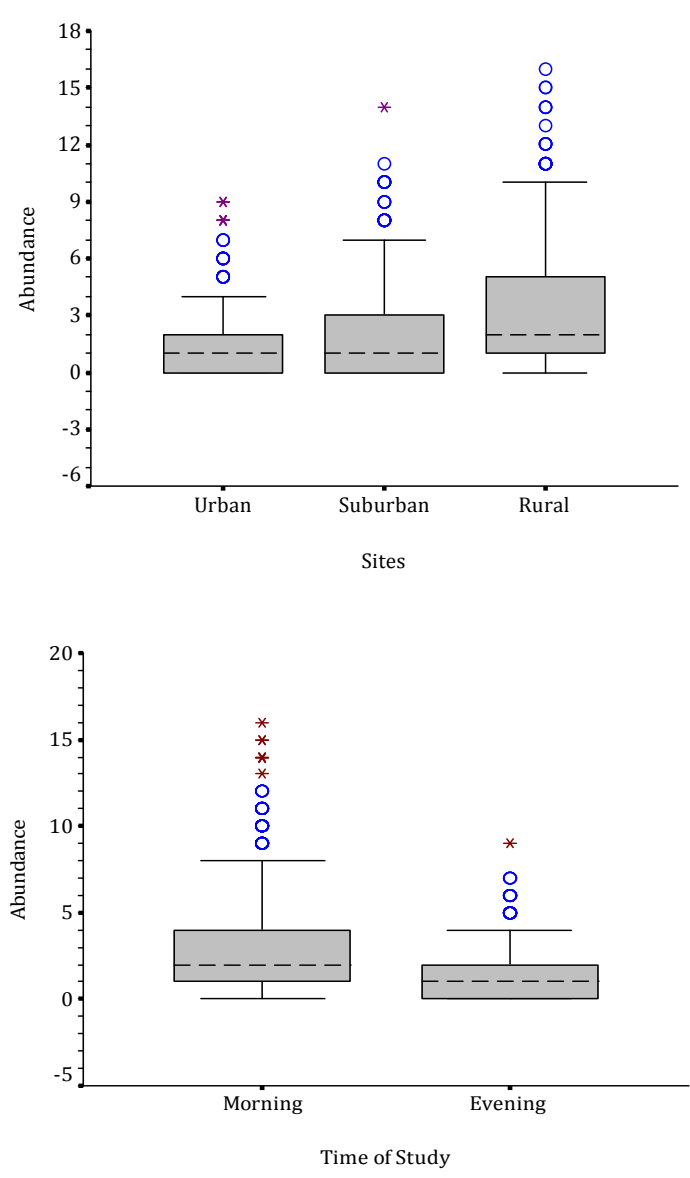

Fig. 8. Box-plot representation of difference in abundance of butterflies with sampling site (a) and sampling time (b). The blue marks are outliers, the brown marks are extreme values and the box represents the lower (25\%) and upper (75\%) quartile with the median values marked as line inside the box. The bars represent range.
$(\mathrm{P}<0.05)$ among the three sites (urban vs. rural, $|\mathrm{q}|=4.14$; urban vs. suburban, $|\mathrm{q}|=1.49$ and suburban vs. rural, $|\mathrm{q}|=$ 2.66; $\mathrm{df}=1079,2 ; \mathrm{SE}=0.2$ ), justifying that the relative abundance of the flower density remained heterogeneous among the three sites. Multiple comparison among the months also revealed significant differences $(\mathrm{P}<0.05)$ for most of the instances except for the summer months (March, April) against the monsoon (July through September) and post monsoon (November, December). This may possibly be an indication about the seasonal dependency of reproduction and population abundance of the butterfly species.

The density of the butterfly species exhibited a significant correlation (Pearson product moment correlation) with the flower density and the L. camara plants as well as among themselves (Table 7). Using five different categories of flower density as explanatory variables, the discriminant analysis enabled classification of 10 butterfly species. The Fisher's distance among the butterfly pairs remained significant for many pairs (Table 8 ). The first two extracted factors (F1 and F2 - 92.423 and 5.312\%, respectively) explained more than $97 \%$ of discrimination of butterfly species as a response to the gradient of flower density of L. camara. The biplot (Fig. 9) portrays the differences among the butterfly species in terms of abundance as explained by the abundance of the flowers of L. camara in the surveyed sites.

\section{Discussion}

The relative abundance of butterflies varies with the number of the host plant species in unit area as observed in different geographical locations (Yamamoto et al., 2007; Bhardwaj et al., 2012; Patel, Pandya, 2014). The relative resource value of the host plant and the preference by the butterfly 
T a b l e 8. The results of Discriminant Analysis showing Fisher's distance, standardised canonical correlations and Eigen values of the flower density as explanatory variables for the observed variations in the selected butterfly species. Low (low) denotes flower numbers ranging from 1-5, medium low (medlow) denotes from 6-9, medium high (medhigh) from 10-15, high low (highlow) denotes from 16-24, and high medium (highmed) denotes 25-70. The values in bold indicate significance at $\mathrm{P}<0.05$ level.

\begin{tabular}{|l|c|c|c|c|c|c|c|c|c|}
\hline Fisher's distances: & CPO & CNE & DEU & PPO & JAT & PDE & JAL & DCH & ALI \\
\hline Cepora nerissa & $\mathbf{3 . 9 3 9}$ & & & & & & & & \\
\hline Delias eucharis & 0.780 & 1.535 & & & & & & & \\
\hline Papilio polytes & 0.249 & $\mathbf{5 . 5 7 6}$ & 1.482 & & & & & & \\
\hline Junonia atlites & 1.717 & $\mathbf{8 . 4 1 6}$ & $\mathbf{2 . 8 5 3}$ & 1.025 & & & & & \\
\hline Papilio demoleus & 0.130 & $\mathbf{4 . 1 9 3}$ & 0.856 & 0.120 & 1.309 & & & & \\
\hline Junonia almana & $\mathbf{8 . 3 6 6}$ & $\mathbf{2 3 . 2 3 9}$ & $\mathbf{1 2 . 9 5 1}$ & $\mathbf{6 . 3 5 7}$ & $\mathbf{4 . 3 4 0}$ & $\mathbf{8 . 0 0 7}$ & & & \\
\hline Danaus chrysippus & 0.723 & $\mathbf{2 . 2 2 6}$ & 0.171 & 1.144 & $\mathbf{2 . 3 3 5}$ & 0.620 & $\mathbf{1 1 . 7 8 4}$ & & \\
\hline Appias libythea & 1.403 & 0.770 & 0.268 & $\mathbf{2 . 3 1 9}$ & $\mathbf{4 . 3 3 1}$ & 1.458 & $\mathbf{1 5 . 8 1 9}$ & 0.656 & \\
\hline Graphium agamemnon & 1.044 & 1.359 & 0.575 & 2.039 & $\mathbf{4 . 7 6 9}$ & 1.426 & $\mathbf{1 4 . 9 0 1}$ & 1.050 & 0.422 \\
\hline
\end{tabular}

\begin{tabular}{|l|c|c|c|c|c|}
\hline \multicolumn{6}{|l|}{ Standardised canonical discriminant function coefficients: } \\
\hline Flower number & F1 & F2 & F3 & F4 & F5 \\
\hline Low & 0.172 & 0.028 & 0.396 & 0.183 & $\mathbf{0 . 8 8 9}$ \\
\hline Medlow & 0.478 & $\mathbf{0 . 7 3 4}$ & -0.483 & -0.060 & 0.149 \\
\hline Medhigh & 0.485 & 0.375 & $\mathbf{0 . 6 6 7}$ & 0.020 & -0.458 \\
\hline Highlow & 0.586 & -0.317 & -0.259 & $\mathbf{0 . 7 0 8}$ & -0.122 \\
\hline Highmed & $\mathbf{0 . 7 0 1}$ & -0.436 & -0.002 & -0.588 & 0.092 \\
\hline
\end{tabular}

\begin{tabular}{|l|c|c|c|c|c|}
\hline & F1 & F2 & F3 & F4 & F5 \\
\hline Eigenvalue & 0.457 & 0.026 & 0.006 & 0.004 & 0.001 \\
\hline Discrimination (\%) & 92.423 & 5.312 & 1.244 & 0.814 & 0.206 \\
\hline Cumulative \% & 92.423 & 97.736 & 98.980 & 99.794 & 100.000 \\
\hline Canonical correlation coefficient & 0.560 & 0.160 & 0.078 & 0.063 & 0.032 \\
\hline
\end{tabular}

species results in a correspondence of the butterfly and host plant diversity (Smallidge, Leopold, 1997; Yamamoto et al., 2007). When viewed at a spatial scale, the similarity in the abundance of the butterfly and the host plants is found in urban, forest and hill landscapes (Thomas et al., 2001; Pywell et al., 2004; Pöyry et al., 2005; Öckinger, Smith, 2006). In parity with these observations, the results of the present study suggest that the relative load of butterfly species varied with the available host plants and its relative abundance (Fig. 4). In each of the sampling units, the relative affinity of the butterflies towards the host plants differed considerably, with the highest preference observed for L. camara (Table 2). The abundance of butterflies in patches (bushes) with L. camara was higher compared with the patches without L. camara (Fig. 5) providing an indication of the relative stronger resource value of the plant in terms of organising the butterflies. Butterfly species assemblages vary with the characteristic vegetation pattern that may promote the coexistence of multiple species depending on the resource value of the vegetations. As observed in the present instance, the density of the butterflies varied in correspondence with the plant species assemblages, though the highest value is observed for L. camara. In all instances, the butterfly species 


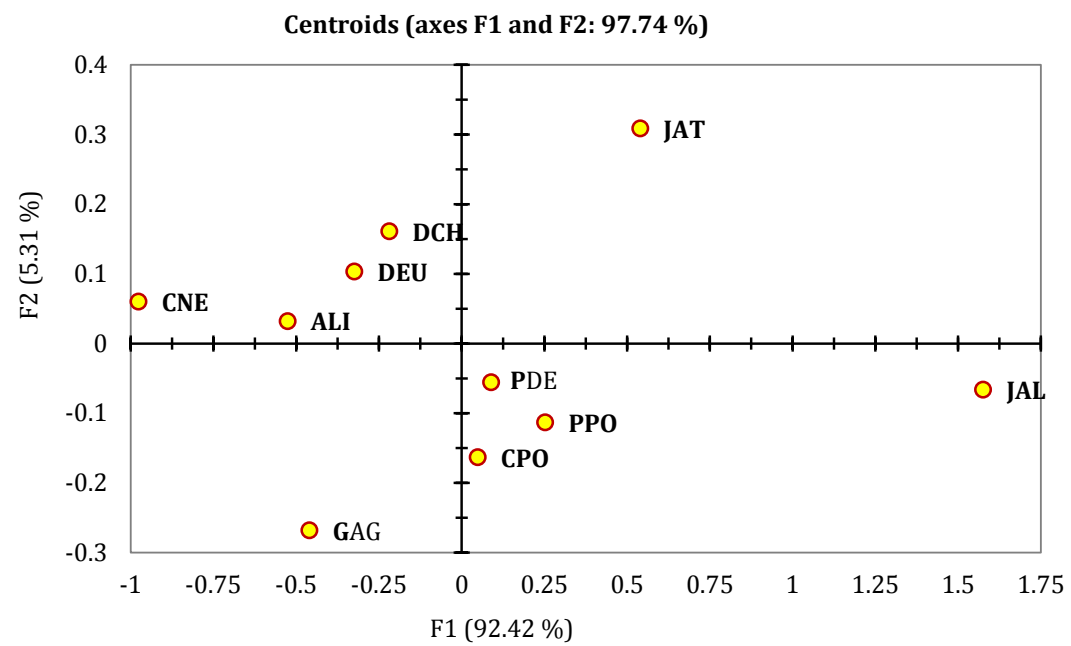

Fig. 9. Biplot representing the ordination of Butterflies as explained through the extent of flowering density of Lantana camara (Wilk' $\lambda=0.661 ; \mathrm{F}_{40,1551}=3.337 ; \mathrm{P}<0.0001$ ).

load remained inclined towards the relative number of $L$. camara present in the sampling units, justifying the significance of the plant as a resource for the butterflies. The association of the butterfly species Precis almana L. (Junonia almana), Catopsilia pyranthe pyranthe L. with L. camara is known since long (Dronamraju, 1958), which is further substantiated in the present study. These butterflies (Dronamraju, 1958, 1960) and many other species (Mathur, Mohan Ram, 1978; Mohan Ram, Mathur, 1984; Fuhro et al., 2010; Jothimani et al., 2014) are linked with L. camara for pollination and for the larval development. Thus, the association of butterflies and their relative preference for L. camara as a resource for food and larval development make it a strong contender for the host plant in sustaining the butterflies, though the number of species and the degree of the preference may vary.

Irrespective of the sites of observation, it was evident that at least 10 different butterfly species consistently frequented L. camara plants in varying numbers depending on the time of flowering and locations of the plants. The sites and the flower density remained crucial for the observed abundance of at least four butterfly species namely Delias eucharis, Papilio demoleus, Junonia atlites, Graphium agamemnon. This is a possible reflection of the dependence of these butterfly species on the phenology of Lantana camara. On the whole, the abundance of the butterflies varied with the suburban, urban and rural sites as well as with the months. Differences in the abundance and richness of the butterfly species were linked with the number of flower and flowering time of L. camara plant in all the sites. Empirical evidences suggest that the frequency of flower visit by the butterflies varies with the seasons and may be attributed to the abundance (Barrett, Helenurm, 1987) and colour of flowers (Dronamraju, 1958; Mathur, Mohan Ram, 1978; Mohan Ram, Mathur, 1984). At proximate level, it appears that the phenology of L. camara modulates the abundance of butterflies, which is why a synchrony in the abundance of butterfly and flowers 
of L. camara was observed (Fig. 6). The pattern of butterfly abundance in L. camara reflects that the strength of the mutual relationship varies with the time (Fig. 8b). As evident from field experiments, butterfly dispersal and relative density is dependent on the phenology of the flowering plants (Peterson, 1997). The association of butterflies and Lantana facilitates reciprocal benefits for survival as a consequence of which the mutual relationship may be strongly coupled with the abundance of both the groups irrespective of the sites and the geographical locations concerned. A strong increment in the number of dependent taxa of butterfly with the plant was observed that provides a suitable reason for considering L. camara in preservation of the dependent butterflies and secure the conditions of sustainable use of the butterfly resource.

In many regions of the world, butterfly species have evolved in a way to match with the changing composition of the host plants and depending more on the alien invasive species. As elaborated through the studies on butterflies and host plants in California, USA, alien plants serve as host for about 34 to $40 \%$ of the total butterfly species richness (Shapiro, 2002; Graves, Shapiro, 2003). Native butterfly may opt for the invasive plants that may enable increased reproductive success through increased chances of multivoltinism and decreased chances of predation provided the alien host plants exhibit certain traits different from the native host plants (Graves, Shapiro, 2003). In many instances, the butterfly larval prey detection by the predators and parasitoids are mediated by the chemical cue from the plants, which may reduce if the butterfly species switches to the invasive plant as new host species (Graves, Shapiro, 2003; Bezemer et al., 2014). Equally, the establishment and perpetuation of the invasive plants is facilitated by the associated butterfly species that ensures cross pollination and reduces the chances of pollination rate of the existing local host plants. Therefore, for the alien plant species, butterfly-mediated increased reproductive success brings about a benefit that may be favoured by natural selection. Different species of butterflies facilitate the pollination process in L. camara, most of which are nectar feeder and exhibit selective preference for the flowers depending on the colours (Dronamraju, 1958, 1960; Fuhro et al., 2010). The mutual dependence can be a driving force for the perpetuation of both butterflies and the weed L. camara in the areas of common occurrence. Availability of L. camara in the spaces of urban green may facilitate the propagation and sustenance of the population of different species of butterflies, particularly in the urban areas where the stringent control of the invasive weed is discounted (Shapiro, 2002). Although, these butterflies are polyphagous in nature, the association with L. camara may reduce competition in case of low abundance of other plant species within their natural range of distribution. Pollinator communities and plant-pollinator interactions are susceptible to human-induced habitat disturbances (Morgan, 1999; van Rossum, Triest, 2010; Hennig, Ghazoul, 2011). With increased level of industrialisation and pressure of development in Kolkata and adjoining areas (Dutta, 2006), it is imperative that alteration in the composition of plant community is obvious. Thus, dependence on the alien plants may benefit the butterfly in such situations where the local plants are facing the disturbance through anthropogenic activities. Such proposition is based on the views of utilising the benefits of exotic species (Prévot-Julliard et al., 2011). It is pertinent to mention that the mutualistic relationship between the butterfly and $L$. camara is a result of co-evolutionary process and consequently, the availability and occurrence of L. camara will ensure sustenance of the butterflies with higher probability. Thus, the mutual relation between butterfly and L. camara can be considered as a basis for the conservation planning and management of butterflies. 
The selection of plant species for urban gardens and artificial patches vary with the purpose and utility. However, under circumstances where the urban greening excludes prioritising particular plant species and discounts the tradeoffs of invasive and native species, growth of $L$. camara will continue at large, particularly if the urban areas lack proper management of gardens and bushes. The extent of abundance of L. camara observed in the present context supports that the plant will continue to propagate at large in different patches and bushes. Even for the last 55 years, the plant is available as a component of the bush species (Dronamraju, 1960), which, in part, can be attributed to the butterfly species that facilitate pollination process. The existence of $L$. camara in high abundance is also a reflection of the failure of complete elimination at a local scale. As a result, it is highly probable that L. camara will continue to host a range of dependent taxa, including butterflies. Considering the dwindling vegetation in urban landscapes in developing countries, the contribution of the invasive species may not be ignored completely, particularly considering the conservation of multiple species. Therefore, irrespective of the strategies of urban greening, presence of the plants such as L. camara may provide valuable services (Patel, 2011; Kannan et al., 2014), including maintenance of different species of butterflies.

\section{Conclusion}

The association of the butterfly species with the invasive plant species L. camara, is known since long in Kolkata, India, which is further demonstrated in the present study. In comparison with many other shrubs and associated plants in the study sites, the relative load of butterfly was significantly higher for $L$. camara. At least 25 butterfly species were found to be associated with $L$. camara in varying numbers depending on the urban rural gradient. The relative abundance of the butterflies remained proportional to the density of flowers of $L$. camara irrespective of the sites. The correspondence of L. camara and the associated butterflies in the sampling sites indicate the possibility of their use as surrogate plants for conservation of butterflies in urban areas.

\section{Acknowledgements}

The authors acknowledge the anonymous reviewer for valuable comments to enhance the manuscript to the present form. The authors are grateful to the respective Heads, Department of Zoology, University of Calcutta, Kolkata, and The University of Burdwan, Burdwan, India for the facilities provided, including DST-FIST and UGC-SAP (DRS I \& II). GKS and SM acknowledge the partial support of West Bengal Biodiversity Board, West Bengal, India in executing the research work. SM acknowledges the financial assistance of UGC through SAP-RFSMS and of University of Calcutta through University Research Fellowship in carrying out this work (Sanction No. UGC/1143/Fellow (univ) dt 25.09.2014.).

\section{References}

Addinsoft, SARL (2010). XLSTAT software. Version 10.0. Paris, France.

Andersson, S. \& Dobson H.E.M. (2003). Behavioral foraging responses by the butterfly Heliconius melpomene to Lantana camara floral scent. J. Chem. Ecol., 29(10), 2303-2318. DOI: 10.1023/A:1026226514968.

Barrett, S.C.H. \& Helenurm K. (1987). The reproductive biology of boreal forest herbs 1. Breeding systems and pollination. Can. J. Bot., 65, 2036-2046. DOI: 10.1139/b87-278.

Bezemer, T.M., Harvey, J.A. \& Cronin J.T. (2014). Response of native insect communities to invasive plants. Annu. Rev. Entomol., 59, 119-141. DOI: 10.1146/annurev-ento-011613-162104.

Bhardwaj, M., Uniyal, V.P., Sanyal, A.K. \& Singh A.P. (2012). Butterfly communities along an elevational gradient in the Tons valley, Western Himalayas: Implications of rapid assessment for insect conservation. J. Asia-Pac. Entomol., 15, 
207-217. DOI: 10.1016/j.aspen.2011.12.003.

Bloch, D., Werdenberg, N. \& Erhardt A. (2006). Pollination crisis in the butterfly-pollinated wild carnation Dianthus carthusianorum? New Phytol., 169, 699-706. DOI: 10.1111/j.1469-8137.2006.01653.x.

Boggs, C.L. \& Gilbert L.E. (1987). Spatial and temporal distribution of Lantana mites phoretic on butterflies. Biotropica, 19, 301-305.

Dronamraju, K.R. (1958). The visits of insects to different coloured flowers of Lantana camara L. Curr. Sci., 27, 452-453.

Dronamraju, K.R. (1960). Selective visits of butterflies to flowers: a possible factor in sympatric speciation. Nature, 186, 178. DOI: $10.1038 / 186178 \mathrm{a} 0$.

Dutta, P. (2006). Urbanization in India. In Regional and sub-regional population dynamic population process in urban areas. European Population Conference, Liverpool, UK 21-24 June.

Faegri, K. \& Van Der Pijl L. (1979). The principles of pollination ecology. Oxford: Pergamon Press.

Faeth, S.H., Bang, C. \& Saari S. (2011). Urban biodiversity: patterns and mechanisms. Ann. N. Y. Acad. Sci., 1223, 69-81. DOI: $10.1111 /$ j.1749-6632.2010.05925.x.

Fuhro, D., de Araújo, A.M. \& Irgang B.E. (2010). Are there evidences of a complex mimicry system among Asclepias curassavica (Apocynaceae), Epidendrum fulgens (Orchidaceae), and Lantana camara (Verbenaceae) in Southern Brazil? Rev. Bras. Bot., 33(4), 589-598. DOI: 10.1590/S0100-84042010000400007.

Gaston, K.J., Warren, P.H., Thompson, K. \& Smith R.M. (2005). Urban domestic gardens (IV): the extent of resource and its associated features. Biodivers. Conserv., 14, 3327-3349. DOI: 10.1007/s10531-004-9513-9.

Godefroid, S. \& Koedam N. (2007). Urban plant species patterns are highly driven by density and function of built-up areas. Landsc. Ecol., 22, 1227-1239. DOI: 10.1007/s10980-007-9102-x.

Goulson, D. \& Derwent L. (2004). Synergistic interactions between an exotic honeybee and an exotic weed: pollination of Lantana camara in Australia. Weed Res., 44, 195-202. DOI: 10.1111/j.1365-3180.2004.00391.x.

Graves, S.D. \& Shapiro A.M. (2003). Exotics as host plants of the California butterfly fauna. Biol. Conserv., 110, 413-433. DOI: 10.1016/S0006-3207(02)00233-1.

Haq, S.M.A. (2011). Urban green spaces and an integrative approach to sustainable environment. J. Environ. Protec, 2, 601-608. DOI: 10.4236/jep.2011.25069.

Haribal, M. (1992). Butterflies of Sikkim Himalaya and their natural history. Gangtok: Nature Conservation Foundation.

Hegde, R., Suryaprakashi, S., Achoth, L. \& Bawa K.S. (1996). Extraction of forest products in the forests of Biligirirangan Hills, India. 1: Contribution to rural income. Econ. Bot., 50, 243-251. DOI: 10.1007/BF02907328.

Hennig, E.I. \& Ghazoul J. (2011). Plant-pollinator interactions within the urban environment. Perspect. Plant Ecol. Evol. Syst., 13, 137-150. DOI: 10.1016/j.ppees.2011.03.003.

Hermy, M. \& Cornelis J. (2000). Towards a monitoring method and a number of multifaceted and hierarchical biodiversity indicators for urban and suburban parks. Landsc. Urban Plann., 49, 149-162. DOI: 10.1016/S0169-2046(00)00061-X.

Jothimani, K., Ramachandran, V.S. \& Rajendran A. (2014). Role of butterflies as pollinators in Maruthamalai Hills of Southern Western Ghats. Acad. J. Entomol., 7(1), 7-16. DOI: 10.5829/idosi.aje.2014.7.1.82289.

Kannan, R., Shackleton, C.M. \& Shaanker R.U. (2014). Invasive alien species as drivers in socio-ecological systems: local adaptations towards use of Lantana in Southern India. Environment, Development and Sustainability, 16, 649-669 DOI: $10.1007 / \mathrm{s} 10668-013-9500-\mathrm{y}$.

Kehimkar, I. (2008). The book of Indian butterflies. Mumbai: Bombay Natural History Society.

Kinnear, P.R. \& Gray C.D. (2000). SPSS for windows made simple. Release 10. Sussex: Psychology Press.

Kunte, K. (2000). Butterflies of Peninsular India. Hyderabad: University Press.

Legendre, P. \& Legendre L.F.J. (1998). Numerical ecology. Amsterdam: Elsevier.

Mack, R.N., Simberloff, D., Lonsdale, W.M., Evans, H., Clout, M. \& Bazzaz F.A. (2000). Biotic invasions: causes, epidemiology, global consequences and control. Ecol. Appl., 10(3), 689-710. DOI: 10.1890/1051-0761(2000)010[0689:BICEG C]2.0.CO;2.

Mathieu, R., Freeman, C. \& Aryal, J. (2007). Mapping private gardens in urban areas using object-oriented techniques and very high-resolution satellite imagery. Landsc. Urban Plann., 81, 179-192. DOI: 10.1016/j.landurbplan.2006.11.009.

Mathur, G. \& Mohan Ram H.Y. (1978). Significance of petal colour in Thrips-pollinated Lantana camara L. Ann. Bot., 42, 1473-1476.

McFrederick, Q.S. \& LeBuhn G. (2006). Are urban parks refuges for bumble bees Bombus spp. (Hymenoptera: Apidae)? Biol. Conserv., 129(3), 372-382. DOI: 10.1016/j.biocon.2005.11.004.

Mohan Ram, H.Y. \& Mathur G. (1984). Flower-insect interaction in pollination. Proc. Indian Acad. Sci. Anim. Sci., 93(4), 359-363.

Morgan, J.W. (1999). Effects of population size on seed production and germinability in an endangered, fragmented grassland plant. Conserv. Biol., 13, 266-273. DOI: 10.1046/j.1523-1739.1999.013002266.x. 
Murali, K.S. \& Siddappa Setty R. (2001). Effect of weeds Lantana camara and Chromelina odarata growth on the species diversity, regeneration and stem density of tree and shrub layer in BRT sanctuary. Curr. Sci., 80, 675-678.

Nelson, S.M. \& Wydoski R. (2013). Butterfly assemblages associated with invasive Tamarisk (Tamarix spp.) sites: comparisons with Tamarisk control and native vegetation reference sites. Journal of Insects, 2013, 1-10. DOI: $10.1155 / 2013 / 561617$.

Öckinger, E. \& Smith H.G. (2006). Landscape composition and habitat area affect butterfly species richness. Oecologia, 149, 526-534. DOI: 10.1007/s00442-006-0464-6.

Patel, S. (2011). A weed with multiple utility: Lantana camara. Rev. Environ. Sci. Biotechnol., 10(4), 341-351. DOI: 10.1007/s11157-011-9254-7.

Patel, A.P. \& Pandya N.R. (2014). Assessment of temporal \& spatial variation in species richness and diversity of butterfly host plants. International Journal of Plant, Animal and Environmental Sciences, 4(3), 235-245. www.ijpaes.com.

Penz, C.M. \& Krenn H.W. (2000). Behavioral adaptations to pollen-feeding in Heliconius butterflies (Nymphalidae, Heliconiinae): an experiment using Lantana flowers. J. Insect Behav., 13(6), 865-880. DOI: 10.1023/A:1007814618149.

Peterson, M.A. (1997). Host plant phenology and butterfly dispersal: causes and consequences of uphill movement. Ecology, 78(1), 167-180. DOI: 10.1890/0012-9658(1997)078[0167:HPPABD]2.0.CO;2.

Pollard, E. (1977). A method for assessing changes in the abundance of butterflies. Biol. Conserv., 12, 115-134. DOI: 10.1016/0006-3207(77)90065-9.

Pollard, E. \& Yates T.J. (1993). Monitoring butterflies for ecology and conservation. London: Chapman and Hall.

Pöyry, J., Lindgren, S., Salminen, J. \& Kuussaari M. (2005). Responses of butterfly and moth species to restored cattle grazing in semi-natural grasslands. Biol. Conserv., 122, 465-478. DOI: 10.1016/j.biocon.2004.09.007.

Prévot-Julliard, A.C., Clavel, J., Teillac-Deschamps, P. \& Julliard R. (2011). The need for flexibility in conservation practices: exotic species as an example. Environ. Manag., 47, 315-321. DOI: 10.1007/s00267-011-9615-6.

Proctor, M., Yeo, P. \& Lack A. (1996). The natural history of pollination. London: Harper Collins.

Pywell, R.F., Warman, E.A., Sparks, T.H., Greatorex-Davies, J.N., Walker, K.J., Meek, W.R., Caewell, C., Petit, S. \& Firbank L.G. (2004). Assessing habitat quality for butterflies on intensively managed arable farmland. Biol. Conserv., 118, 313-325. DOI: 10.1016/j.biocon.2003.09.011.

Raizada, P., Sharma, G.P. \& Raghubanshi A.S. (2008). Ingress of Lantana in dry tropical forest fragments: edge and shade effects. Curr. Sci., 94, 180-182.

Sahid, I.B. \& Sugau J.B. (1993). Allelopathic effect of Lantana (Lantana camara) and siam weed on selected crops. Weed Sci., 41,303-308.

Sajjad, A., Saeed, S. \& Burhan-u-din S. (2012). Yearlong association of butterfly populations with flowering plants in Multan, Pakistan. Pak. Entomol., 34(2), 105-110. www.pakentomol.com.

Schemske, D.W. (1976). Pollinator specificity in Lantana camara and L. trifolia (Verbenaceae). Biotropica, 8(4), $260-264$.

Shapiro, A.M. (2002). The Californian urban butterfly fauna is dependent on alien plants. Divers. Distrib., 8, 31-40. DOI: 10.1046/j.1366-9516.2001.00120.x.

Smallidge, P.J. \& Leopold D.J. (1997). Vegetation management for the maintenance and conservation of butterfly habitats in temperate human-dominated landscapes. Landsc. Urban Plann., 38, 259-280. DOI: 10.1016/S0169-2046(97)00038-8.

Thomas, J.A., Bourn, N.A.D., Clarke, R.T., Stewart, K.E., Simcox, D.J., Pearman, G.S., Curtis, R. \& Goodger B. (2001). The quality and isolation of habitat patches both determine where butterflies persist in fragmented landscapes. Proc. $R$. Soc. London B, 268, 1791-1796. DOI: 10.1098/rspb.2001.1693.

Tiple, A.D., Khurad, A.M. \& Dennis R.L.H. (2009). Adult butterfly feeding-nectar flower

associations: constraints of taxonomic affiliation, butterfly, and nectar flower morphology. J. Nat. Hist., 43(13), 855-888. DOI: $10.1080 / 00222930802610568$.

Tiple, A.D. (2012). Butterfly species diversity, relative abundance and status in Tropical Forest Research Institute, Jabalpur, Madhya Pradesh, central India. Journal of Threatened Taxa, 4(7), 2713-2717. DOI: 10.11609/JoTT.o2656.2713-7.

van Rossum, F. \& Triest L. (2010). Pollen dispersal in an insect-pollinated wet meadow herb along an urban river. Landsc. Urban Plann., 95, 201-208. DOI: 10.1016/j.landurbplan.2010.01.004.

van Strien, A.J., van Duuren, L., Foppen, R.P.B. \& Soldaat L.L. (2009). A typology of indicators of biodiversity change as a tool to make better indicators. Ecol. Indic., 9, 1041-1048. DOI: 10.1016/j.ecolind.2008.12.001.

Weiss, M.R. (1997). Innate colour preferences and flexible colour learning in the pipevine swallowtail. Anim. Behav., 53, 1043-1052. DOI: 10.1006/anbe.1996.0357.

Yamamoto, N., Yokoyama, J. \& Kawata M. (2007). Relative resource abundance explains butterfly biodiversity in island communities. Proc. Natl. Acad. Sci. USA, 104(25), 10524-10529. DOI: 10.1073/pnas.0701583104.

Yeargan, K.V. \& Colvin S.M. (2009). Butterfly feeding preferences for four Zinnia cultivars. J. Environ. Hortic., 27 (1), $37-41$. Zar, J.H. (1999). Biostatistical analysis. New Delhi: Pearson Education. 